\title{
“GROMMING": EL MINOTAURO EN INTERNET. EL DERECHO PENAL DEL ENEMIGO FRENTE AL PEDERASTA DE LA ERA DIGITAL
}

Pedro Javier Granja*

\begin{abstract}
Resumen: Se estima que 2300 millones de personas se conectan a internet en el mundo actual, y sus contactos son cada vez más anónimos. El mayor porcentaje de los usuarios son los nativos digitales, esto es, seres humanos que crecieron en medio de la sociedad de la red. Nos referimos a niños y adolescentes, lo cual ha provocado que el pederasta del siglo pasado traslade su campo de acción a un terreno que presenta inconmensurables dificultades para identificarlo y neutralizarlo. El minotauro digital acecha, su voracidad no se frena, se asocia en redes internacionales, usa la tecnología para burlar controles. Contacta niños bajo diversos disfraces, los prepara para que satisfagan sus deseos sexuales en un pavoroso ritual de manipulación emocional que concluye generalmente en el chantaje al menor y a su posterior abuso sexual. El grooming, en muchas legislaciones actuales, presenta serias deficiencias en cuanto a su tipificación.
\end{abstract}

* Máster en Criminología por la Studiorum Università di Bologna y la Università degli Studi di Padova. Doctorando en Derecho Penal por la Universidad de Buenos Aires. Profesor de posgrado en materia punitiva. Quito (Ecuador). Correo-e: consejoabogaciaecuador@outlook.com. Fecha de recepción: 7 de julio de 2020. Fecha de aceptación: 12 de enero de 2021. Para citar el artículo: PEDro JAVIER Granja. "'Gromming': el minotauro en internet. El derecho penal del enemigo frente al pederasta de la era digital", Revista Derecho Penal y Criminología, vol. 41, n. ${ }^{\circ} 111$, julio-diciembre de 2020, Bogotá, Universidad Externado de Colombia, pp. 61-108. DoI: https://doi.org/10.18601/ 01210483. v41n111.03. 
En este trabajo presentamos un estudio desde las coordenadas del funcionalismo normativo sistémico, más concretamente desde el derecho penal del enemigo, exponiendo algunas ideas para profundizar el debate y aportar a la materialización de una campaña real de neutralización contra estos auténticos focos de peligro. Se objetará que nuestra posición entiende al pederasta como Carl Schmitt lo hacía respecto de un determinado grupo racial, lo cual, como lo demostraremos con amplia literatura, es absolutamente falso, pues el enemigo para Jakobs es un delincuente que se aparta macabra y duraderamente del derecho y es absolutamente indiferente su estatura o cualquier otra cuestión física. Se criticará que esta posición está basada en prejuicios, pero ¿es acaso posible encontrar un ordenamiento penal en el mundo que se fundamente exclusivamente en juicios? La respuesta es que no, esto no es factible, y se entiende con un ejemplo muy sencillo: nadie discute que en Italia existen diversas organizaciones criminales, no es una sola mafia sino varias empresas delictivas, unas más violentas que otras, unas con más ramificaciones con bandas albanesas o españolas que otras. ¿Es esto un prejuicio? Sus hechos, las investigaciones, las evidencias encontradas nos dicen que no, que la peligrosidad de todas estas bandas no se discute, pero hay algunas, como la Ndrangheta, que reviste una especial amenaza a la configuración de una sociedad pacífica. En algún momento también existían prejuicios sobre las Brigadas Rojas, el ETA o las FARC y luego, al reflejarse como amenazas de incalculables proyecciones delictivas, se terminó normando las conductas de su complejo espectro criminal con otra velocidad, lo cual está, desde nuestro enfoque, absolutamente justificado.

Palabras clave: grooming; abuso; sexual; infantil; internet; derecho penal; enemigo.

\title{
GROMMING: THE MINOTAUR ON THE INTERNET. CRIMINOLOGICAL PROFILE OF THE PEDERAST IN THE DIGITAL AGE AND HIS FIGHT FROM THE CRIMINAL LAW OF THE ENEMY
}

\begin{abstract}
Approximately, 2.3 billion people connect to the internet in today's world, with increasingly anonymous contacts. The largest users percentage are digital natives, that means, human beings who grew up in the middle of the network society. We refer to children and adolescents, which has caused the pedophile of the last century to transfer his field of action to a field that presents immeasurable difficulties identifying and neutralizing the problem. The digital Minotaur lurks, its voracity does not stop, it associates in international networks, it uses technology to circumvent controls. It contacts children under various disguises, prepares them to satisfy its sexual desires in a terrifying ritual of emotional manipulation that generally ends in blackmail of the minor and subsequent sexual abuse. Grooming, in many current legislations, presents serious deficiencies regarding its typification. In this work we present a study
\end{abstract}


from the coordinates of systemic normativism, presenting some ideas to go deeper into the discussion and contribute to the fight against these criminals.

Keywords: grooming; abuse; sexual; childish; internet; enemy; criminal, law.

\section{INTRODUCCIÓN}

No son pocas las publicaciones en las que se intenta despedazar la tesis del derecho penal del enemigo atribuyéndole concepciones decididamente falsas, desprovistas de sustento científico y que han inaugurado un verdadero concurso para ver cuál es más enemigo del derecho penal del enemigo. Se dice, por ejemplo, que se trata de una postura inspirada en Carl Schmitt, que plantea la supresión de todas las garantías fundamentales y por obvia derivación avala procesos penales similares a los de la Inquisición y, por si no bastase, algunos llegan a afirmar que el derecho penal del enemigo enarbola la bandera de la pena de muerte contra cierto tipo de infractores. La terminología que usa Jakobs ha despertado, como no podía ser de otro modo, incontables críticas. Entre sus detractores están los que dicen que es una simple adaptación de Carl Schmitt y otros que prefieren encontrarle un mero intento de acoplar a Luhmann con el derecho penal. Entre quienes pretenden quitarle valor a la obra de Jakobs acusándola de vínculos con el pensamiento de Carl Schmitt se encuentran Guillermo Portilla Contreras, Francisco Muñoz Conde, Kai Ambos, Eduardo Demetrio Crespo o Bernd Müssig, quienes analizan la categoría schmittiana de El concepto de lo político con el concepto de enemigo de la obra jakobsiana.

En medio de esta interesantísima discusión que ha provocado una avalancha de reflexiones se encuentra un número siempre creciente de víctimas, personas que han sido desplazadas de sus territorios, asesinadas en masa por grupos criminales que pretenden ampararse en supuestas justificaciones políticas para cometer todo tipo de desviaciones, niños, mujeres, hombres mutilados, destinados al comercio sexual, atentados dinamiteros, otros tantos extorsionados por la mafia, nunca faltan los que mueren por falta de asistencia médica dado que delincuentes de cuello blanco decidieron transferir esos caudales públicos a sus cuentas privadas y con el manto de la tecnología, y ahora tenemos un nuevo tipo de pederasta, el digital, que genera, como veremos en líneas siguientes, daños de consecuencias imposibles de calcular con precisión. En el Reino Unido, la Internet Watch Foundation (IWF), una organización que intenta "minimizar la disponibilidad de contenidos potencialmente criminales en la red", cierra sitios de internet donde se comparten o se venden imágenes de abuso sexual infantil. Hace diez años, las redes de pederastas y pornografía infantil ya eran un azote real: 14.602 sitios virtuales activos ofreciendo chats y compartiendo y comercializando imágenes y videos de niños con contenido lúbrico. Si bien se logra localizar y clausurar una decena diaria de estos servidores, un promedio de 59 páginas nuevas se añadía a la lista por día. Las víctimas son de todo el mundo, con preferencia niños de países en vías de desarrollo. 
Enfrentar a este tipo de delincuentes debería ser una impostergable cuestión en la agenda política global, pero lo que hace hasta hoy es sencillamente efectivista, esto es efectivo a la vista. Para materializar en la praxis un programa mínimamente realista es preciso hacerlo con una secuencia de acciones diferentes a las que se usan frente a infracciones menores que no pasan de ser meros deslices normativos. No decimos que si se llegasen a aplicar completamente las propuestas de Jakobs ya no tendríamos delitos escandalosos, esto sería poco serio. Las expectativas normativas siempre serán defraudadas. Lo que pretendemos, me aventuro a decir que todos, es reducir en la mayor medida posible esas defraudaciones, y eso se logra neutralizando con mayor firmeza a los responsables.

Desde nuestro enfoque, la tesis más sólida para enfrentar, de alguna manera, a criminales tan peligrosos que socavan las bases mismas de la existencia civilizada está en el derecho penal del enemigo, tesis para la que es absolutamente indiferente la raza o la posición política del delincuente siendo que su transformación en enemigo tiene motivos claramente punitivos. En el caso de un abusador sexual infantil, es claro que no sólo irrespeta el círculo de la doble contingencia, como lo veremos más adelante, sino que además se vale de una relación absolutamente asimétrica con un heteroadministrado para reducir a un objeto que le proporciona beneficios lúbricos o comerciales.

A modo de necesaria aclaración, no podemos dejar de señalar que existe quien hace un examen muy parecido al de un arqueólogo que busca entre las piedras cualquier marca para poder probar que alguna vez los dinosaurios pasaron al frente de nuestras casas. Sostienen, por ejemplo, que dado que Carl Schmitt distinguió entre Freund y Feind, esto es entre amigo y enemigo, le otorgó partida de nacimiento a una concepción del derecho penal mucho más dura con ciertos delincuentes ${ }^{1}$ que luego habría sido recogida por Jakobs. Bernd Müssig da por descontada la relación entre el concepto de derecho penal del enemigo de Jakobs y la facultad de declaración estatal del enemigo introducida por Schmitt como criterio determinante de distinción de lo político ${ }^{2}$. Kai Ambos encuentra magnitudes idénticas entre el pensamiento de Schmitt y el de Jakobs, y manifiesta una profunda preocupación por la búsqueda que él encuentra en ambos autores de "la exclusión de grupos enteros de la población"3, lo que no logra acreditar en ningún momento, y en el cenit de su rechazo al DPE llega

1 Muñoz Conde, Francisco. “Es el Derecho penal internacional un Derecho penal del enemigo?”, en Revista Penal 21, 2008, pp.93-102, disponible en [http://www.uhu.es/revistapenal/index.php/penal/ article/view/342/333].

2 Müssig, Bernd. "Derecho penal del enemigo: concepto y fatídico presagio. Algunas tesis", en M. Cancio Meliá y C. Gómez-Jara Díez (coords.), Derecho penal del enemigo: el discurso penal de la exclusión, Montevideo-Buenos Aires, B de F, vol. 2, 2006, pp. 371-390.

3 Ambos, Kai. "Derecho penal del enemigo”, en M. Cancio Meliá y C. Gómez-Jara Díez (coords.), Derecho penal del enemigo: el discurso penal de la exclusión, Montevideo-Buenos Aires, B de F, vol. 1, 2006, pp. 11916. 
declara a Schmitt “abuelo espiritual del Derecho penal del enemigo", lo cual, palabras más, palabras menos, implicaría entender a Jakobs simple y llanamente como una adaptación de sus postulados y en lo que respecta a este artículo no llevaría a pensar que Jakobs catalogaría como focos de peligro a los pederastas, por una cuestión racial o religiosa, lo que es manifiestamente falso al tenor del milimétrico examen de sus obras. El pederasta, por el contrario, es perseguido por sus actos contra la indemnidad sexual de niños y "si ya no existe la expectativa seria, que tiene efectos permanentes de dirección de la conducta, de un comportamiento personal -determinado por derechos y deberes-, la persona degenera hasta convertirse en un mero postulado, y en su lugar aparece el individuo interpretado cognitivamente"4, y es este, no otro, el rasgo que lo convierte en una fuente de daño potencial para los demás.

En la tesis de Jakobs, el enemigo, en el caso, el pederasta digital, es siempre un delincuente, mientras que en la obra de Schmitt no lo es. Bastaría revisar la tesis de Schmitt con un mínimo de detenimiento para advertir que él propone al menos dos tipos de "enemigo". Uno de carácter internacional que vive lejos y separado de la sociedad germana y, por supuesto, del amigo ${ }^{5}$. Se trata del extranjero que vive en su propio territorio y quien es por consiguiente plenamente identificable. El otro tipo de enemigo de Schmitt es el interno, pero su referencia es racial, orientada a descalificar a los judíos y gitanos, también a los homosexuales, es decir a los enemigos del Reich, algo que no se encuentra jamás en ninguna frase de Jakobs. Por el contrario, cuando Jakobs habla de un enemigo conceptualiza a un individuo, como el pederasta o el miembro de un grupo terrorista, que se ha apartado de manera presumiblemente permanente del derecho y, por lo tanto, ya no ofrece seguridad cognitiva sobre su comportamiento personal a los demás que sí se mantienen fieles a la configuración misma de la sociedad ${ }^{6}$. El enemigo externo de Schmitt no es un criminal al que hay que aniquilar, sino un enemigo legítimo al que se le debe profundo respeto. Es el otro del ius publicum europaeum, es decir, el derecho internacional que comienza en el siglo XVII y finaliza en 1914. No se trata de un extranjero que vive sin pensar en nosotros sino en un enemigo público, espacialmente diferenciado. En definitiva, un enemigo legítimo. A este, a diferencia del enemigo interno, no se le puede aniquilar porque moldea la propia existencia. "El enemigo es nuestra propia pregunta como persona. [...] Enemigo no es algo que tiene que ser eliminado por cualquier razón y aniquilado por su desvalor. El enemigo está a mi propio nivel. Por esta razón, tengo que luchar con él, para encontrar la propia medida, los propios límites y la propia personalidad"7 , dirá Carl Schmitt. En cuanto al otro enemigo, el interno, Schmitt, fiel

4 Jakobs, Günther. Derecho penal del enemigo, Manuel Cancio Meliá (trad.), Madrid, Thompson Civitas, 2003 p. 14.

5 Granja, Pedro. ¿Qué es y qué no es derecho penal del enemigo?, Guayaquil, DPM, 2019, pp. 123 y ss.

6 Jakobs, Günther. "Derecho penal del ciudadano y Derecho penal del enemigo”, cit., p. 42.

7 Schmitt, Carl. "Das Zeitalter der Neutralisierungen und Entpolitisierungen", en C. Schmitt, Der Begriff des Politischen, Berlin, Duncker \& Humblot, 2015, pp. 71-78. 
a las concepciones nazis, no se opone a que sea eliminado, lo cual, como ya hemos visto, se opone a la tesis de la despersonalización propia del DPE.

El análisis schmittiano plantea que existen momentos de la existencia social en los cuales la división entre amigos y enemigos se da en el interior del Estado y esto tiene un grave y doloroso impacto en lo que él denominaba "la unidad nacional", la misma que al quedar desarticulada conduce a la guerra civil. Dado que es imposible que ambos bandos subsistan, el que pierda debe ser suprimido. La guerra civil tiene un solo modo de solución y este es el exterminio de uno de los grupos enfrentados o la renuncia a un gran espacio de su territorio.

En Jakobs, esto no funciona así ni remotamente. Para él, si bien es cierto que todo enemigo es un delincuente, no todo delincuente es enemigo, y el criminal convertido en foco de peligro, para el funcionalismo sistémico normativo, no siempre es un enemigo en todos los aspectos de la existencia. Ni siquiera un homicida debería ser considerado enemigo, puesto que "ningún estado sucumbe por un caso de estas características"8. En un Estado de derecho real, el pederasta conserva en muchos aspectos de su vida todos sus derechos, como tener acceso a alimentación sana, a entretenimiento, a condiciones de salud básicas mientras está privado de su libertad. Jamás se plantea la aniquilación del enemigo, porque eso le quitaría toda legitimidad al Estado para poder sancionar, para que el infractor tenga la posibilidad de entender su error comunicativo indemnizando a la víctima y así mantener la configuración de la sociedad. Más allá de este criterio, lo esencial en la determinación del enemigo es que el individuo, caso paradigmático del pederasta, no ofrezca garantía cognitiva suficiente de que se comportará como una persona fiel al derecho.

La consecuencia principal de constituirse en enemigo es la pérdida de personalidad para el derecho. Ahora bien: esa personalidad no se pierde, en ningún caso, de modo definitivo. Para el funcionalismo normativo sistémico hay un evento central en la desviación criminal que es la desobediencia, la declaración de no querer mantenerse fiel a la norma y a la configuración jurídica de la sociedad, y por esa misma razón, pese al crimen cometido, los delincuentes pueden seguir siendo personas si logran comportarse de manera tal que demuestren que su propósito es cambiar su conducta brindando una garantía cognitiva a los demás de que no serán agredidos.

Al narcotraficante, al mafioso, al terrorista, al delincuente económico, al pederasta se les califica como focos de peligro porque han atacado con una intensidad inaceptable la estructura normativa, y mantener la tesis de que el análisis de esos actos debe hacerse con las mismas reglas que a los que cometen delitos de bajo o mínimo impacto es inaceptable. Como podemos apreciar fácilmente, encontrar similitudes

8 Jakobs, Günther. "Derecho penal del ciudadano y Derecho penal del enemigo", cit., p. 35. 
entre estos autores es una tarea absolutamente vana y absurda. Mientras Schmitt veía en el enemigo un criminal, Jakobs hace del criminal un enemigo. Por último, mientras Schmitt les niega toda posibilidad a los enemigos internos para abandonar esa etiqueta, Jakobs sostiene que el Estado puede seguir tratando como persona al delincuente cuando su delito se considere "un defecto personal transitorio". Pero ese tratamiento ya no resulta posible ni deseable "cuando el defecto personal ocasional se convierte en duradero o cuando diferentes defectos se suceden en una cadena casi sin fin o, en todo caso, incalculablemente larga" 9 .

Solo como un dato suelto, desde el DPE se propone la despersonalización que supone privar al delincuente de ciertos medios para cometer ulteriores crímenes y se rechaza rotundamente la impersonalización, que implica realmente la pena capital al privarlo de todos los medios. Bastaría recordar a los enconados críticos del maestro de Bonn que es Hegel una de sus principales fuentes filosóficas y en Die Philosophie des Rechts, un maduro Hegel nos dice "Cuando alguien mata a otro y se mata al primero, el mal no se ha eliminado" 10 . Y es que una idea de la retribución en la pena fundada en el talión es inconcebible en un derecho penal moderno, y quienes pretenden endilgarle a Jakobs esta deficiencia nos muestran dos cosas: o están decididos, quién sabe por qué motivos, a distorsionar su teoría a costa de acabar con su propio prestigio, o solo reproducen de otros cuestiones que, en un afán errado por dotar de cierta cientificidad a sus trabajos, no pasan de ser meras ocurrencias. Desde el derecho penal del enemigo se aborda la cuestión de cómo el Estado debe enfrentar a ciertos criminales, quienes con sus hechos claramente nos remiten un mensaje a todos como sociedad y se convierten en serias y verificadas amenazas a la paz de quienes sacrificamos parte de nuestra libertad natural en aras de convivir pacíficamente con los demás, de quienes esperamos, en función de la doble contingencia, una conducta al menos similar.

Corresponde todavía proporcionar un par de cuestiones aclaratorias más sobre el mismo eje: Es muy difícil negar que existe una cepa de delitos que son particularmente odiosos, que nos hacen reflexionar inmediatamente en cómo actuaríamos si la víctima fuere uno de nuestros seres más cercanos. Vemos todos los días noticias de niños secuestrados que luego de varios días de desgarrador drama aparecen desmembrados, lanzados en lugares de difícil acceso con claras muestras de haber sido víctimas de abuso sexual. ¿Acaso solucionamos esto eliminando físicamente a los potenciales autores? El derecho repudia, desde decenas de años, la venganza como método para castigar estas conductas: “[T]oda retribución mediante la causación de un dolor, sin finalidad cara al futuro, es venganza y no puede tener otro fin que no sea el de consolarse del sufrimiento que uno mismo padece viendo el sufrimiento

9 Jakobs, Günther. "Coacción y personalidad. Reflexiones sobre una teoría de las medidas de seguridad complementarias a la pena”, cit., p. 10. Véase también Jakobs, Günther. “¿Derecho penal del enemigo? Un estudio acerca de los presupuestos de la juridicidad”, cit., p. 104.

10 Hegel. Die Philosophie des Rechts, 2005, p. 91. 
ajeno que uno mismo ha causado" "11, decía Schopenhauer, y es un criterio que no admite disenso desde la razón. Por eso, los planteamientos que vamos a desarrollar en este trabajo girarán en torno a cómo debería articularse un modelo punitivo tomando como referencia las coordenadas del funcionalismo normativo, sustentando cada afirmación con la brújula jakobsiana, siendo que, luego de leer reiteradamente a este autor, de haber recibido clases de él, consideramos que nos brinda argumentos válidos para poder evitar el retorno, siempre posible, al estado de barbarie.

¿Por qué y cómo castigar, por ejemplo, a los pederastas, desde la concepción funcionalista radical?

Primero desde la idea de Schadensersatzrecht (derecho de daños), existe el deber de restaurar el derecho fracturado, derrumbado por la conducta criminal. Mientras el ciudadano que actúa respetando la norma contribuye a la estabilización de un orden de libertades para todos, quien busca a un niño deliberadamente para degradarlo a objeto para su placer sexual se rebela ante axiomas sustanciales de toda juridicidad, por consiguiente debe tener claro que se confirme a su costa la indisolubilidad del vínculo entre el disfrute de la libertad y el fiel cumplimiento de su deber de cooperación ${ }^{12}$. A diferencia de un ciudadano que estafa a otro cuando le logra vender una bicicleta que no sirve o se apropia de su teléfono móvil en un bar al primer descuido de su propietario, el pederasta y en el caso concreto el abusador sexual infantil que opera al amparo de las tecnologías de la comunicación no ha incurrido en un mero desliz normativo, no se va a detener en su actividad, de arranque alarmantemente nociva. Por el contrario, no sólo nos dice con su primer acto que no le interesa comportarse conforme a la norma primaria, sino que, por si no bastase, se mantendrá operando del mismo modo dado que el que se le aplique la sanción contenida en la norma secundaria le resulta indiferente pues sabe que en gran parte de los ordenamientos ésta es realmente mínima y que los estados no están, en la praxis, muy interesados en capturarlos y procesarlos, lo cual se comprueba con la escalofriante tasa de impunidad que se desprende de la revisión de las cifras de delitos de este corte denunciados ( $\sin$ considerar la enorme tasa de crímenes que no se ponen en conocimiento de las autoridades) y los casos efectivamente sancionados. A todo lo anterior cabría añadir que en no pocas ocasiones el pederasta digital lesiona al menor en una ciudad sudamericana o africana mientras se encuentra manteniendo una vida muy tranquila en una capital europea, lo cual favorece con mayor intensidad aún su impunidad. Cierto es que "la función principal del derecho, en especial del derecho penal, consiste en posibilitar a los ciudadanos que puedan conducir su vida en consonancia con su propio parecer"13 ${ }^{13}$ pero esto que es un derecho supremo

11 Schopenahuer. Die Welt als Wille und Vorstellung, 1991, p. 451.

12 Henkel, Heinrich. Einführung in die Rechtsphilosophie, 2. ${ }^{a}$ ed., Gebundene Ausgabe, 1977, p. 412.

13 Pawlik, Michael. Ciudadanía y Derecho Penal, Atelier Libros Jurídicos, Barcelona, 2016, p. 85, en idénticos términos, el mismo Pawlik en Das Unrecht des Burges, 2012, p. 99. 
ineludiblemente lo obliga "a dejar al otro como está, a no empeorar su integridad"14, y dado que los lesionados son personas incapaces de entender la defraudación de la exigencia de doble contingencia en la que unos nos comportamos de acuerdo con un compromiso general esperando de los demás exactamente lo mismo, es evidente, desde el plano conceptual, que los delitos de este tipo de autores tienen amplias posibilidades de quedar anclados en la penosa cifra de la injusticia, lo cual socava las bases de una estructura mínimamente seria o que se precie de serlo.

Ahora bien: no me resulta placentero iniciar este recorrido con un caso real, pero lo estimo necesario para exponer a qué tipo de infractores se dirige esta propuesta de combate penal: Amanda tenía 11 años cuando conoció a otro "niño" en internet. Se sentía desgarradoramente sola y quizás por eso aceptó esta amistad. Cuando cumplió 12 años, su "amigo" le pidió que mostrara su pecho por la cámara. La niña accedió. Poco después su vida se transformó en una pesadilla cuando este anónimo empezó a chantajearla con envíarles la foto a todos sus contactos si ella no aceptaba hacerle un baile especial ${ }^{15}$. Era Navidad. En la madrugada, agentes de la policía tocaron su puerta para comunicarle a su padre que la foto había sido enviada a todos sus contactos. La niña cayó en depresión, ansiedad y en un trauma profundo. Tuvo que cambiar de ciudad para intentar iniciar una nueva vida en otra escuela. Apenas unos meses después, el pederasta volvió a aparecer. Evidentemente, se trataba de un delincuente con conocimientos avanzados en redes informáticas. Tenía en su poder los nombres de los nuevos contactos de Amanda y el de su nueva escuela. No contento con eso, había creado una página en Facebook que utilizaba su fotografía en topless como imagen de perfil, y no tardó en enviar la imagen nuevamente a todos los compañeros de clase de la nueva escuela. La niña se convirtió en el centro de tortuosos ataques de matoneo y acoso, por lo cual surgió en ella el deseo de autolesionarse.

La máscara de "niño" era solo parte de un disfraz utilizado por un adulto, plenamente responsable, que era alérgico a la felicidad de los menores, se dedicaba a destruirlos de todos los modos posibles. Criminales de este tipo no se detienen solo mediante la simple contradicción de sus actos comunicativos abiertamente conspiradores contra la paz social, sino que su captura y posterior condenada debe entenderse como una confirmación de la configuración social y además debe servir para frenar las posibilidades de subsecuentes violaciones de la norma infringida. El combate a esta cepa de delincuentes no es un tema que se reduzca, como equivocadamente se sostiene en una serie de interesantes trabajos académicos, a la eliminación física de los ellos. De hecho, nada más alejado a la verdad que repetir que el derecho penal del enemigo

14 Hegel, Georg Wilhelm Friedrich. Vorlesungen Uber Rechtsphilosophie 1818-1831: Die Rechtsphilosophie Von 1820, Mit Hegels Vorlesungsnotizen 1821-1825, 1974, Karl-Heinz Ilting fue el redactor. La cita la recogemos de la página 176.

15 Sobre el particular se recomienda Bullied Canadian teen leaves behind chilling YouTube video CNN.com (consulta: 13 de octubre de 2012). 
se apoya en la pena de muerte pues esto es rechazado rotundamente por esta tesis, punto sobre el cual nos detendremos más adelante.

El tema es que la vigencia de la norma, siendo esencial si queremos vivir en una sociedad real, no es un fin en sí misma. Lo que se busca es evitar un vaciamiento de las normas primarias que contienen generalmente el nemimen laedere, esas construcciones que nos prohíben violar, matar, robar, agredir, esto es hacer daño a otro, organizar defectuosamente en esferas de libertad ajenas, aplicando con fuerza la norma secundaria que castiga estos supuestos. Permitir que estos delincuentes gocen de las mismas garantías que el resto de personas que nos sometemos al imperio de la ley equivale a contribuir a que la generalidad de ciudadanos empiece a dudar de la importancia de mantenerse fieles a un ordenamiento jurídico concreto. En otras palabras, no perseguirlos con la fuerza que se necesita para impersonalizarlos supone alentar reflexiones como ¿para qué debo respetar la norma si otros no lo hacen y no les ocurre absolutamente nada o sus sanciones son realmente intrascendentes?

Retomemos el drama de Amanda, que, tristemente, no es un caso de laboratorio sino perturbadoramente real. Sus padres intentaban llevarla de una escuela a otra porque el pederasta volvía a aparecer conectado a cualquiera de sus conversaciones por cuanta plataforma digital usted pueda imaginar. En un video, la niña llegó a contar que todo estaba mejor, aunque se sentaba sola durante la hora del almuerzo. También refirió que sus compañeros la convirtieron en centro de burlas y críticas y que llegaban a golpearla salvajemente, que incluso tuvo que esconderse varias horas en una zanja donde luego su padre la encontró para llevarla a casa. Intentó suicidarse tomando blanqueador para la ropa. Los médicos le aplicaron un lavado gástrico que impidió su deceso. Al salir del hospital, vio cómo en las redes sociales las burlas por ese suceso no paraban.

El 10 de octubre de 2012, Amanda murió por suicidio mediante ahorcamiento. Le dejó a una sociedad incompetente para capturar a un delincuente que se dedicó a convertir su vida en un calvario un video donde cuenta todo su drama ${ }^{16}$.

En casos como este, ¿es válido aplicar el derecho penal del enemigo?

“ ¿Se trata de un crimen que requiere la intervención de la justicia, o constituye un ataque que exige una declaración de guerra?"17, preguntaba en un conocido artículo publicado en el Washington Post, uno de los más prestigiosos catedráticos de la

16 Bullying Canada, una conocida organización cuya función es combatir el acoso escolar en este país, desarrolló diversas investigaciones, las más recientes arrojan resultados que horrorizan: uno de cada siete niños canadienses, de entre 11 y 16 años de edad, es víctima del acoso escolar o por internet.

17 Fletcher, George P. Washington Post, edición impresa del 12 de octubre del 2001, con idéntico texto en Fletcher, George P. Justice in the Face of Enemy Fire, manuscrito inédito, 2005, p. 29. 
Universidad de Columbia. La interrogante se formulaba luego de unas semanas de los atentados terroristas del 9-11 en Estados Unidos. Habilitar un Feindstrafrecht o derecho penal del enemigo contra delincuentes que por su extrema peligrosidad mutan hasta convertirse en auténticos monstruos cuyo propósito central es derrumbar la coexistencia civilizada es una discusión que lamentablemente no se da en nuestras facultades de Derecho o parlamentos con la rigurosidad científica que el conflicto moderno exige.

Se objeta, por ejemplo, que el derecho penal del enemigo es absolutamente incompatible con el Estado de derecho, pero ¿es que acaso los allanamientos de morada que se realizan todos los días en Argentina, Colombia, Italia, Ucrania, Rusia o México crucifican las garantías de probables responsables? Pues es evidente que no, que son operaciones necesarias en el combate a diversas formas de delincuencia, como también lo son la interceptación de comunicaciones de sujetos sospechosos de pertenecer a grupos dedicados a actividades criminales o el registro de secuestradores, terroristas o violadores previamente condenados de los que se valen las agencias policiales para ubicar a potenciales autores de delitos similares. Acciones de este tipo son parte de la propuesta jakobsiana, y, como nos podemos dar cuenta, están reguladas y autorizadas casi en todos los ordenamientos.

Admitir que el derecho penal del enemigo está presente en todos los ordenamientos punitivos del mundo occidental es impostergable. Que se aplique en ínfimas dosis es otra historia, que se confundan sus coordenadas básicas con populismo penal es la lógica consecuencia de la ausencia de investigaciones serias sobre el particular al menos en nuestra región. Sancionar la conducta ya desarrollada que pone en evidencia la alta acidez de un determinado delincuente para el sistema social es un postulado propio del DPE, que de ninguna manera violenta los principios rectores que alimentan lo que conocemos como debido proceso.

El derecho penal del enemigo, entonces, debe entenderse como una noción descriptiva que propone ciertamente el anticipo de punibilidad ante posibles autores de desviaciones que ponen en grave riesgo la seguridad general, que nos permite distinguir entre aquellos individuos que se apartan de la norma con tanta peligrosidad que hacen ineludible distinguirlos de aquellos deslices normativos que cometen todos los días los ciudadanos, como, para plantear un ejemplo, si se quiere bizantino, quien propina un puntapié a otro en una discusión en un bar está desautorizado por la norma, es palmario que el contenido comunicativo de su acto está desaprobado en toda sociedad civilizada pero el trato que debe recibir por él no es el que se le debe dar a un sujeto que integra una organización que planea instalar un artefacto explosivo en un lugar concurrido o a aquellos que están dedicados a la pornografía infantil.

Cuando sostenemos que un abusador sexual infantil asesina, sin que sea necesario arrancarle la vida físicamente a su víctima, es porque inevitablemente, la despojará de las ganas de existir. Su peligrosidad reviste otras dimensiones que exceden al del 
simple infractor ciudadano que viola la norma pero con un estándar menos corrosivo para la estructura social.

Arribado a este punto se objetará que estamos haciendo un análisis basado en prejuicios, un punto sobre el cual es preciso proponer, a modo de pertinente aclaración, el siguiente ejemplo: cuando conocemos que en los alrededores de una escuela se estaría expendiendo drogas, ¿no hacemos un pedido a las autoridades para que intervengan? Hay hechos cuantificables y demostrables milimétricamente que nos permiten afirmar que tenemos sociedades con altas tasas de consumidores infantes y adolescentes y que en los perímetros de sus centros de estudios se concentran rufianes que ofertan sustancias estupefacientes. ¿Es eso un prejuicio? Podríamos decir que no, que no lo es, pero aun en el caso de que lo sea, ya en el plano estrictamente punitivo se entienden como supuestos traducidos con criterios normativos para mantener la configuración social, pues de otro modo, con la total inacción policial e investigativo, la estructura de convivencia dejaría de ser una civilización.

El profesor Jakobs nos ha dejado claro en múltiples oportunidades que para hacer un análisis apenas riguroso sobre un determinado fenómeno delictivo es preciso que el jurista no utilice expresiones sobre "lo que es bueno y lo que es malo". Valoración y descripción se mantienen siempre en escenarios diferentes, por eso el derecho penal del enemigo es tan objetivo como la cultura en la que se desarrolla. Las expresiones criminales de la década de los sesenta del siglo pasado no son las mismas a las que nos enfrentamos hoy. Se objetará entonces que la objetividad del derecho penal está anclada a los valores subjetivos de una época cultural determinada y la respuesta que debe darse a esto desde el normativismo sistémico es que la cultura no es mera subjetividad porque su punto de partida es una relación entre personas, una objetividad, una relación interpersonal.

Por otro lado, ¿es acaso posible encontrar un ordenamiento penal en el mundo que se fundamente exclusivamente en juicios? La respuesta es que no, no es factible, y se entiende con otro ejemplo muy sencillo: nadie discute que en Italia existen diversas organizaciones criminales, no es una sola mafia sino varias empresas delictivas, unas más violentas que otras, unas con más ramificaciones con bandas albanesas o españolas que otras. ¿Es esto un prejuicio? Sus hechos, las investigaciones, las evidencias encontradas nos dicen que no, que la peligrosidad de todas estas bandas no se discute, pero hay algunas, como la 'Ndrangheta, que reviste una especial amenaza a la configuración de una sociedad pacífica en Calabria y en el resto del país. En algún momento también existían prejuicios sobre las Brigadas Rojas, el ETA o las FARC y luego, al reflejarse como amenazas de incalculables proyecciones delictivas, se terminó normando las conductas de su complejo espectro criminal con otra velocidad, lo cual está, desde nuestro enfoque, absolutamente justificado.

En línea con lo apenas referido ut supra, veamos rápidamente otro caso: un sujeto de 21 años contacta a una niña de 12 años que dijo tener 14. El sujeto le miente a la 
menor, dado que le aseguró que él también tenía 14 años. Se encuentran por primera vez en una cita que se había pactado como una simple charla para conocerse y tienen relaciones sexuales. El caso habría sido parte de la estadística del silencio de no ser porque la menor resulta con un embarazo ectópico. El Tribunal lo absuelve, bajo dos argumentos sin duda controvertidos. Dicen los jueces que hubo error de tipo pues el acusado no sabía que la niña tenía 12 años cuando tuvo relaciones sexuales con ella y además que la víctima, sin importar la edad del acusado, de todos modos habría tenido relaciones sexuales con él ${ }^{18}$.

¿Cómo no podría advertir, un adulto, que mantiene un cruce epistolar digital con una menor de 12 años?

Incluso suponiendo que sea tan precario intelectualmente para no advertirlo, al momento de encontrarse con ella, físicamente, ¿tampoco es capaz de entender que su "par" apenas está comenzado a vivir? Sostener, por consiguiente, la posibilidad de comisión imprudente de este crimen, en los casos en que se alega error sobre la edad, es por decirlo de alguna manera, bastante discutible.

¿Se podría combatir a sujetos que violan, torturan, secuestran y asesinan niños con el marco jurídico penal que impera en buena parte de los sistemas punitivos vigentes?

Los datos nos dan una respuesta lacerante. Pero además el mero hecho de permitir que deambulen por escuelas o parques es, in extremis, irresponsable por parte del Estado. Si los tenemos de vecinos, es obvio que nos veremos obligados a cambiarnos de casa o que nos uniremos con otros residentes del sector para estar en alerta máxima por la integridad y la vida de nuestros hijos pequeños. Se trata, pues, lamentable pero ciertamente, ya no de personas, sino de focos de peligro que ponen en grave riesgo la seguridad cognitiva de todos al no responder al freno de la norma. Por otro lado, decir que la castración química es suficiente para resolver el problema es absurdo y solo deja en evidencia el desconocimiento de quienes defienden esta "solución". Bastaría decir que violar es la acción de insertar un objeto en la boca, vagina o ano de la víctima. Objeto que puede ser el pene o lo que haga sus veces. Es decir, estas personas, en libertad, pueden violar con un palo, con los dedos, con las manos, con cualquier cosa.

En el derecho no se cree en la posible futura bondad del delincuente, en el derecho se plantean posiciones. Y la nuestra es que aquel criminal que en su etapa previa ha tenido la posibilidad de reconocerse a sí mismo como persona pero con su conducta grave y reiterada se aleja de la sociedad, ese delincuente que aprovechando de su condición abusa sexualmente de un niño, secuestra a un par de jovencitas, las obliga a

18 Sentencia de Audiencia Provincial de Valencia, España SAP Valencia n. ${ }^{\circ}$ 722/2013, del 24 de octubre (ARP 2013/1338). 
ingresar en el portamaletas de su propio automóvil, para luego recorrer toda la ciudad haciendo que saquen su dinero de sus cuentas bancarias, el delincuente económico, aquel que le quita la vida a un padre de familia, a un comerciante a cambio de una recompensa monetaria, todos esos sujetos deben ser combatidos con un derecho penal diferente, de otra velocidad.

¿Cómo y por qué debe utilizarse otro marco conceptual para esta decisión?, ¿por qué es adecuado aplicar un marco penal distinto ante esta clase de infractores?, ¿qué justifica un tratamiento diferente entre autores de diversos delitos?

Un pederasta, por la peligrosidad que representa, debe ser despersonalizado, privado de ciertos medios para evitar que cometa más crímenes, no impersonalizado (la impersonalización supondría su eliminación vía pena de muerte, esto es privarlo de todos los medios), pero debe ser neutralizado, de ser posible, antes de que cometa otros delitos. Despersonalizarlo implica suspenderle ciertas garantías.

Su tratamiento debe ser diferenciado, debe ser investigado en forma intensa y sin descanso porque generalmente actúan en redes. Si se mantiene la despersonalización, los interrogatorios pueden extenderse sin problema y los datos que pueden llegar a confesar nos permitirían evitar que otros delincuentes dañen a otras víctimas potenciales.

Con estos dolorosos antecedentes, se extiende una invitación al lector para reflexionar sobre las dimensiones de estas conductas criminales y cómo, en una sociedad tan compleja como la del imperio de las pantallas, nuestros hijos pueden ser, en cualquier instante, víctimas silenciosas de estas.

\section{EL INTERNET COMO ESCENARIO DELICTUAL}

Una investigación policial de cuatro años concluye en mayo del 2011 cuando la policía de Lincolnshire, en el centro este de Inglaterra, anunció el desmantelamiento de una red que usaba internet para distribuir y vender material pornográfico infantil. La conocida posteriormente como Operación Alpina provocó el cierre de un sitio virtual prácticamente inaccesible y permitió la identificación y protección para 132 niños británicos. Cincuenta y cinco pederastas fueron oficialmente capturados pero las autoridades señalaron que posiblemente la cifra era mucho mayor, pues la banda tenía una red con ramificaciones monumentales. Más de un millón de imágenes de niños desnudos y 6000 películas con contenido lúbrico fueron decomisadas ${ }^{19}$.

No es nuestra intención satanizar el uso del internet, lo analizamos solo como el medio que permite que los contactos sean cada vez más anónimos, que, por supuesto,

19 El efecto internet en la pedofilia, disponible en [https://www.bbc.com/mundo/noticias/2011/07/110 726_pedofilia_internet_sao]. 
da cabida a un nuevo tipo de enemigo que muerde y huye, que se esconde y acecha en un escenario de dimensiones inconmensurables. Mientras al pederasta "clásico" lo podíamos identificar, localizar y capturar con equipos locales de investigación, al minotauro digital obligatoriamente debemos estudiarlo desde una visión mucho más compleja para poder combatirlo con mínimo éxito. Arribado a este punto, es preciso recordar que los niños y en particular los adolescentes se encuentran en un periodo del desarrollo humano caracterizado por la búsqueda de la propia identidad, lo cual hace que se multiplique su necesidad de comunicación e interacción social; esto los lleva a usar internet ${ }^{20}$ con más frecuencia que los adultos y a permanecer conectados durante más tiempo ${ }^{21}$.

El panorama en el tercer mundo no se diferencia del escenario estadounidense ni del europeo en cuanto al uso del internet ${ }^{22}$. La ecuación es sencilla: cuantos más usuarios infantiles existan, más casos de child grooming se van a producir. La mayoría quedará impune con un sistema de investigación policial desfinanciado y un Estado con legislaciones, en muchos casos, histéricamente permisivas, que muestran muy poco interés en proteger a sus menores.

Mientras tanto, las páginas de pederastas en línea que han sido desactivadas según el servidor de ubicación nos brindan estos preocupantes datos: en América del Norte existen 7058 sitios web, que equivalen al $42 \%$ mundial; Europa, incluyendo Rusia, la sigue muy de cerca, con 6829 servidores, equivalentes al 41\%; Asia tiene 2839 puntos de venta de pornografía y encuentros pederastas, lo cual lo ubica en un tercer lugar, con el 17\%; y los datos en América del Sur son de doce sitios web, pero esto no nos debe tranquilizar, dado que con seguridad la cifra es mayor pero la labor policial es, por ausencia de recursos, equipos y capacitación, decididamente marginal ${ }^{23}$.

20 Conforme a un estudio publicado en el año 2008, el 94\% de los adolescentes norteamericanos utilizaba internet, de los cuales un $63 \%$ lo hacía a diario y un $35 \%$ varias veces al día. Por otro lado, de acuerdo con análisis publicados en 2010, el $93 \%$ de los menores que utilizaban internet en EE. UU. lo hacía en más de un lugar, aunque principalmente desde el propio domicilio. Europa ofrece variables similares que se extraen de un estudio publicado en 2008, del que se desprende que el $75 \%$ de los niños europeos utilizaban internet: el $60 \%$ tenía entre 6 y 10 años de edad, el $84 \%$ entre 11 y 14 y el $86 \%$ entre 15 a 17 años.

21 Núñez Fernández, José. Presente y futuro del mal llamado delito de ciberacoso a menores: análisis del artículo 183 bis CP y de las versiones del Anteproyecto de Reforma de Código penal de 2012 y 2013, artículo que se enmarca en el proyecto de investigación "Garantías penales en la creación, aplicación y ejecución del Derecho penal de la Unión Europea”, con referencia DER2012-32977, financiado por el Ministerio de Economía y Competitividad.

22 Ecuador, por ejemplo, con base en los datos que nos proporcionaba su Instituto de Estadísticas y Censos en el año 2011, ya refería la existencia de algo más de cuatro millones de usuarios. Mucha agua ha pasado bajo el puente desde esa fecha. Internet pasó de ser un servicio exclusivo a uno masivo, al menos así lo sostiene el Ministerio de Telecomunicaciones y Sociedad de la Información del mismo país que nos dice que mientras en 2006, apenas el 6,14\% tenía acceso a la red, solo seis años después, el aumento fue del 48,6\%, es decir, para el 2012 el 54,7\% de los ecuatorianos estaba conectado.

23 Tendencias operativas 2010 de Internet Watch Foundation Operational Trends. 
Jakobs y sus discípulos más importantes, como Pawlik, han referido que su visión del derecho penal de ninguna manera es profética, que no tienen la más remota intención de parecerse a Marx o Spengler. Huelga decir entonces que el enfoque jakobsiano plantea que una sociedad puede ser conocida en su real dimensión solo en su decadencia (de allí su famosa referencia al vuelo de Minerva); por ende, el análisis que nosotros hacemos respecto del internet como carretera moderna que permite el libre tránsito de personas decentes, niños, aficionados a la hípica, al arte pop o estudiantes de medicina pero también facilita la preparación y consumación de delitos graves como la pederastia y la pornografía infantil, es central en este breve artículo. No nos atreveríamos jamás a decir que de aquí a cierto número de años el escenario será menos o más conflictivo, solo partimos de una base, lamentablemente, inobjetable: nos enfrentamos a grupos criminales que tienen una ventaja y que deben ser regulados por agencias que garanticen la integridad de los demás, y para eso se precisa de ordenamientos legales que vayan a tono con los tiempos actuales.

¿Cuál es la función que debe desempeñar el derecho penal en una sociedad desde la concepción jakobsiana? Pues el derecho no debe organizarse en función de "datos previos naturales o de cualquier otra clase ajenos a la sociedad"24.

Esto explica por qué hace unas décadas este artículo no habría tenido ninguna posibilidad de realizarse. Si el análisis se hace respecto de un tipo de criminalidad ya conocido pero actualmente reforzado por el avance de la tecnología, es evidente que la plataforma especifica que permite tal desarrollo debe ser referida.

Es que pederastas han existido siempre y hasta tienen su propio club de fans, integrado por quienes los imaginan como deidades, el más reciente ejemplo lo tenemos con la tristemente célebre pizzería parisina que las autoridades han intervenido y descubierto que se trataba de una cueva de depravados que se encontraban allí para hablar de sus víctimas. Hay un hecho que no se puede dejar al margen: el minotauro del siglo pasado merodeaba parques y escuelas, estudiaba para ser profesor de primaria o se preparaba para cualquier actividad que le permitiese estar cerca de menores. Sería absurdo pensar que este tipo de actividades deleznables se haya acabado, pero este artículo gira en torno a un criminal moderno que usa el internet para engañar, ganarse la confianza de niños con el fin de concertar encuentros para abusar sexualmente de ellos en forma física o a través de videos, llamadas o solicitud de material fotográfico, en una relación abiertamente macabra en la que impera el control emocional sobre su víctima ${ }^{25}$.

24 Cfr. Jakobs, Gunther. Derecho penal, Parte General. Fundamentos y teoría de la imputación, Joaquín Cuello Contreras y José Serrano González (trads.), 2. a ed., Madrid, 1997, p. 7.

25 Mendoza Calderón, S. El derecho penal frente a las formas de acoso a menores. Bullying, ciberbullying, grooming y sexting, Valencia, Tirant lo Blanch, 2003, p. 185. 


\section{NATIVOS Y MIGRANTES DIGITALES}

Las sociedades posmodernas tienen como rasgo distintivo ser, por consideraciones que exceden a este artículo, mucho más complejas que las previas, pero la paradoja es que para subsistir necesitan reducir la complejidad. Esto, al margen de discursos, se verifica en la praxis con la distinción en ámbitos concretos que denominamos "subsistemas". El derecho es uno de estos. Cuando hablamos de derecho penal, éste se articula atendiendo a problemas que le exigen una disminución de su peligrosidad, y que tienen "equivalentes funcionales" 26 . En el caso de nuevas formas de criminalidad que son expresiones esperadas del desarrollo social, lo que intentará siempre el derecho penal es facilitar la orientación atacando la complejidad que alimenta y facilita el deseo del delincuente. Por eso, entender categorías como nativos y migrantes digitales es parte de una propuesta funcionalista para poder entender primero el fenómeno y luego activar mecanismos para expectorarlo en la mayor medida de lo posible de la sociedad.

A tono con lo precedente, debemos partir de datos verificados y preocupantes: los niños son los mayores consumidores de internet en el mundo. En el año 2001, Marc Prensky bautizó con el término "nativos digitales" a todas aquellas personas nacidas después de 1990, es decir, aquellos que han nacido en la aldea global del internet, con juegos y encuentros en línea, dificultades para interrelacionarse personalmente, adicción a los teléfonos móviles, entre otras.

La configuración psicocognitiva de los más jóvenes es a todas luces superior, en cuanto al uso de desarrollos tecnológicos, a la de los "migrantes digitales”, personas educadas con pizarras de tiza, que iban a la escuela con un cuaderno de papel y lápiz y que para realizar cualquier investigación debían pernoctar varios días en la biblioteca.

El depredador sexual en el grooming es generalmente un migrante digital, pero un rasgo muy reiterado en su modus operandi es que tiene conocimientos avanzados en todo lo referente a la comunicación digital. Actúa amparado en esta ventaja en comparación a los padres o a quienes tienen las funciones de custodia y protección de los menores.

\section{EL YO ELECTRÓNICO, LA SERPIENTE DE LA MANIPULACIÓN: PERFIL CRIMINAL DEL MINOTAURO DIGITAL}

Si la sociedad se organiza con base en sistemas y subsistemas y estos últimos tienen como tarea limitar, disminuir los grados de complejidad, debemos entender que esto

26 Betancor Curbelo, Diego, "Derecho y sociedad, factores recíprocos. La sociología del derecho en la formación del jurista”, en Revista de Ciencias Jurídicas de la Universidad de las Palmas de Gran Canaria, n. ${ }^{\circ}$ 2, 1997, p. 74. Casi con idéntica posición el profesor Niklas Luhmann, Zweckbegriff und Systemrationalität: über die Funktion von Zwecken in sozialen Systemen, 1973, pp. 270-271. 
se logra con las expectativas. El lector tiene claro que este no es un artículo para exponer el monumental edificio conceptual del profesor Jakobs, por razones de método estamos evocando puntos de imprescindible tratamiento para desarrollar este trabajo. En consonancia, los contactos sociales que le interesan regular al derecho se generan cuando usted acepta al otro como su igual. Usted ocupa, entonces, en lenguaje luhmaniano ${ }^{27}$, el lugar del yo o del ego y la persona con la que hace el contacto sería su alter ego, ambos constituyen entonces un microsistema social ${ }^{28}$. Esto que parece una obviedad nos remite entonces a la cuestión de la doble contingencia en la que ambos esperan algo del otro.

La doble contingencia, en palabras de la profesora Beatriz de la Gandara, supone una metaperspectiva desde la que es fundamental realizar diversas conexiones y selecciones al convertirse en catalizador de las mismas. Así, Ego sabe que Alter conoce que Ego actúa tomando como base la conducta de Alter, por lo tanto Ego deberá operar anticipando, en cierto modo, la conducta ${ }^{29}$.

¿Pero cómo podría darse una relación de doble contingencia entre un adulto y un niño, que es un estatuto ontológico heteroadministrado?

No se trata de enarbolar la bandera del funcionalismo por moda o por desprecio a un cierto grupo de infractores, porque en la academia tenemos claro que ni el odio ni el amor son categorías dogmáticas. En este punto, exponemos simplemente que en un contacto social entre un adulto y un niño hay una defraudación de arranque, una de carácter cognitivo, pues mientras el uno sabe perfectamente lo que está buscando para su gozo, el menor es incapaz de procesar esa situación. Luego esta relación es tan asimétrica que el menor ni siquiera está en grado de entender que su "amigo" está defraudando correlativamente una expectativa normativa al violar abiertamente una norma que le prohíbe el acercamiento con fines lúbricos. Como la víctima ignora que a la expectativa normativa no renunciamos jamás aun en el caso que sea violada, queda vaciada la posibilidad de contradecirla contrafácticamente pues el niño no puede, por lógica elemental, definir la ruptura decisiva que hace posible tal expectativa. Esto genera que crímenes de este tipo sean alarmantemente crueles y que la cadena de ofensa se pueda repetir por años sin persecución penal alguna.

Describir por razones exclusivamente científicas al enemigo al que se debe combatir en este tipo de crímenes es un segundo imperativo. También llamado stranger danger,

27 En nuestro libro ¿Qué es y qué no es derecho penal del enemigo? dejamos claro que Luhmann no es el antecedente filosófico más importante de Jakobs, como sostienen algunos colegas.

28 Izuzquiza, Ignacio. La sociedad sin hombres. Niklas Luhmann o la teoría como escándalo, Barcelona, 1990, pp. 211-212 у 246-247.

29 De la Gándara, Beatriz. "Algunas consideraciones acerca de los fundamentos teóricos del sistema de la teoría del delito de Jakobs", en ADPCP, vol. L, 1997, p. 366. 
el pederasta digital es, a grandes trazos, un depredador sexual de niños al amparo de la red con quien siempre tendrá una relación parecida a la silla de tres soportes del conocido ejemplo de Lacan. No hay forma de que la doble contingencia exista en una secuencia vertical, por lo tanto aquí hay tenemos otra razón sustancial para combatir de otro modo a este tipo de criminales.

La gama de actos sexuales que los pedófilos pueden realizar con los niños es amplia. Puede ir desde actividades como el exhibicionismo o el voyeurismo a otras como realizar caricias, frotar sus genitales contra el niño, masturbación en presencia de estos, sexo oral y penetración anal o vaginal. Un pederasta digital al momento de ser capturado generalmente tiene entre cuatro y cuarenta víctimas previas. Muy probablemente, sin asistencia especializada, sus víctimas podrían convertirse en victimarios. Y es en esta franja donde encontramos a los futuros pederastas más violentos. Un estudio de 2002, realizado por expertos de la talla de Craissati, McClurg y Browne ${ }^{30}$, concluye con un dato que se sospechó desde antaño pero que no deja de provocar profunda preocupación y es que los delincuentes pedófilos que habían sido victimizados sexualmente en la infancia mostraban niveles más altos de hostilidad, disfunción sexual (como mayor presencia de obsesiones sexuales, mayor número de distorsiones cognitivas sobre la sexualidad de los niños y mayor número de agresiones sexuales a niños), malestar personal y una menor empatía hacia las víctimas que aquellos pedófilos que no habían sufrido abusos o agresiones sexuales en su infancia.

Los jueces deben resolver esto o al menos reflexionar sobre esta cuestión cuando se les solicita órdenes para poder intervenir comunicaciones de potenciales pederastas digitales o realizar operaciones encubiertas para su detección y captura. Nuevamente, planteamos razones de derecho, plenamente objetivables y cuantificables para sostener que un derecho penal del enemigo no sólo es necesario sino filosófica y jurídicamente justificado para neutralizar a estos focos de daño.

\section{UN FOCO DE PELIGRO QUE EROSIONE EL SISTEMA SOCIAL}

Si el pederasta digital es excéntrico o no, no tiene ninguna relevancia en el campo jurídico penal. Vamos a plantear a continuación algunos rasgos identitarios con el propósito de seguir analizando a un enemigo que sin duda le lleva franca ventaja a un sistema penal que sucumbe ante la inconmensurable cantidad de cadenas que le impiden luchar contra fenómenos criminales cada vez más lesivos. Si un delincuente sexual toma contacta con el hijo de su vecino, mantiene un pronunciado cruce digital aprovechando que sus padres se han divorciado o por motivos laborales están mayoritariamente ausentes, por ejemplo, y logra que el niño le remita fotos y videos sin

30 Craissati, J.; Mcclurg, G. y Browne, K. "Characteristics of perpetrators of child sexual abuse who have been sexually victimized as children", en Sexual Abuse, 2002, disponible en [https://journals . sagepub.com/doi/abs/10.1177/107906320201400303? journalCode=saxb] 14: 225-239. 
ropa, para luego comercializar en la dark web o pacta un encuentro con fines sexuales no sólo está violando a un menor que quizás a usted le resulte absolutamente ajeno, es indiscutible que su hijo, su sobrino también quedan expuestos como potenciales víctimas y el daño que este sujeto provoca es general y de incalculables dimensiones. En su conocido tratado, Jakobs nos alerta respecto de que "la defraudación, el conflicto y la exigencia de una reacción frente a la infracción de la norma no pueden ser interpretados como una vivencia del sistema individual -persona singular- sino que han de ser interpretados como sucesos en el sistema de relación social"31.

Estamos frente a un delincuente que generalmente tiene infinita paciencia precisamente para poder defraudar el entramado social. ¿Qué es lo que lo impulsa a actuar de este modo? De acuerdo con los estudios de Miró Llinares, el depredador infantil del siglo pasado intimaba con un niño con fines sexuales en el espacio físico como forma de autogratificación que responde a una necesidad de ejercicio de poder, dominio, control o rabia y, por lo general, no era consciente del daño infligido, por lo cual era más fácil de capturar que el actual, que genera al principio mayor empatía con las víctimas y presenta menos distorsiones cognitivas ${ }^{32}$. Sabe que debe ganarse la confianza de su presa. La estudia milimétricamente. Hay un factor reiterado, son más susceptibles al ataque los niños con padres separados, abandonados, con necesidad extrema de afecto o de figura paterna.

Las niñas están más expuestas, presentan entre dos y cuatro veces mayor riesgo de ser víctimas de grooming que los niños, pero investigaciones actuales concluyen que entre el 16 y el $36 \%$ de los niños también son susceptibles de ser víctimas de este tipo de delitos pues el mensaje "no hables con extraños" es más ignorado por ellos. Independientemente del sexo, el pederasta manipula al niño al extremo, sabe que solo cuando la víctima haya entregado muchísima información sobre su situación y sienta que puede confiar en él podrá acceder a esta carnalmente, lo cual además va a explotar vilmente para perpetuar la impunidad gracias al control del silencio del niño, al que hará sentir como culpable, en todo momento, de lo sucedido.

El proceso de abuso sexual en esta manifestación criminal es integral y para esto necesitan degradar al niño a simple objeto que está obligado a producirles placer. Es lo que Wolf, en un magistral estudio, ha bautizado como el "ciclo de la adición” o los esquemas citados por una de las voces autorizadas en esta materia, como la profesora Carolina Villacampa: el "modelo de la precondición” creado por David Finkelhor ${ }^{33}$

31 Jakobs, Gunther. Strafrecht, Allgemeiner Teil Die Grundlagen und die Zurechnungslehre. Lehrbuch,

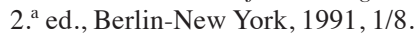

32 Miró Llinares, F. El cibercrimen: fenomenología y criminología de la delincuencia en el ciberespacio, Marcial Pons, Madrid, 2012, p. 255.

33 Finkelhor, David. Child Sexual Abuse: New Theory and Research, The Free Press, New York, 1984, disponible en [https://scholars.unh.edu/soc_facpub/339/], pp. 35 y ss. 
y el "modelo descriptivo de la cadena de ofensa" formulado por Tony Ward y otros ${ }^{34}$. El groomer es metódico. Arma todo un edificio conceptual sobre el menor, cada dato es un ladrillo, se empapa de toda la información posible sobre su víctima: estudia su perfil, sus contactos, sus fotografías, sigue sus comentarios y opiniones en las redes sociales. Estamos frente a un enemigo que se vale de toda una obra de ingeniería digital perversa.

Mostrarse "cool” es lo que sigue. Lanzar preguntas en apariencia inocentes: “¿tienes un perrito o un gatito?”, ¿están juntos tus padres?”, “¿en qué trabaja tu papá?”, “¿cómo se llama tu mamá?”, ‘en qué escuela estás?”.

La víctima ni siquiera se da cuenta cuando el pederasta le pide que se quite la blusa frente a la cámara o que le haga un baile con una impronta que el mismo minotauro determina, siempre con una carga lúbrica, erótica. Es entonces cuando el niño ha perdido todo, porque el groomer lo acosará hasta llevarlo al suicidio si es necesario. Hay padres que descubren esto y tratan de solucionar el asunto eliminando todos los chats y ofreciendo dinero al delincuente, pero en este punto debemos ser claros: lejos de arreglar algo, solo contribuyen a perpetuar el daño contra su hijo y contra otras decenas de menores.

$¿$ No castigamos esto como lo que es, una de las tantas conductas que forman parte del penoso espectro del abuso sexual infantil? Decir que "no" porque no hubo daño físico demuestra una creciente tendencia en la esfera jurídica para mirar hacia otro lado respecto de estos auténticos focos de peligro.

\section{UN EXAMEN DESDE EL DERECHO PENAL MODERNO}

Hay quienes prefieren denominar a los delitos de lesión bajo la nomenclatura de "delitos de resultado". Esto, como magistralmente lo explica el profesor Gimbernat Ordeig, es un error conceptual que puede tener graves consecuencias en la configuración normativa de la sociedad porque en los delitos de peligro también hay resultado $^{35}$, que trastorna la vida de la víctima al poner en grave riesgo sus bienes jurídicos como vida, propiedad, entre otros.

Es importante mencionar esto porque en la mayoría de las legislaciones que tipifican y reprimen el child grooming solo existe delito cuando el pederasta solicita un encuentro físico con el niño con lo que entienden como lícito que un adulto contacte a un menor y mantenga un largo cruce de chats con este, de carácter eróticos

34 Ward, T. et al. "A descriptive model of the offense chain for child molesters", Journal of Interpersonal Violence, 10(4), 1995, disponible en [https://doi.org/10.1177/088626095010004005], pp. 452 y ss.

35 Gimbernat Ordeig, E. Delitos cualificados por el resultado y causalidad, 2. ed., Colección Maestros del Derecho Penal, Buenos Aires, B de F. 
o sexuales, pese a que la experiencia nos dice que el groomer usa esos chats para luego chantajear al niño o a sus padres. En sintonía con esta posición, no faltan los juristas que sostienen que, a lo sumo, esto serían meros actos preparatorios, pero quizás olvidan que

El bien jurídico protegido tiene un doble carácter, el individual, en relación con ese menor, y el supraindividual, en relación con la protección de la infancia, ya que estas conductas no pueden considerarse aisladas y solo en relación con un menor concreto, sino contra la infancia en general, a la que hay que proteger contra los pederastas ${ }^{36}$.

\section{BIEN JURÍDICO QUE SE PROTEGE}

En La imputación objetiva en derecho penal, Jakobs nos dice que "el concepto de bien jurídico no es suficiente para describir el sistema del derecho penal vigente en la actualidad" 37 , tendremos claro que el derecho penal no protege bienes jurídicos sino la desautorización de la norma; no obstante, esto no quiere decir que el funcionalismo penal sostenga que éstos no existen, simplemente lo que entendemos es que no fluctúan libremente en el aire, no están tampoco encerrados en una caja de vidrio. Por eso, siguiendo a Jakobs, no interpretamos el conflicto social en funciones de hechos naturales sino como construcciones humanas, de allí que la dogmática penal tenga como tarea central desarrollar preceptos para reaccionar ante las comunicaciones erradas de los infractores que se creen autorizados a erosionar la norma y despojarla de todo significado. El acto del pederasta o su secuencia de conductas en la cadena de ofensa es un acto comunicativo con un significado claro que merece una respuesta de igual configuración y se la tenemos que ofrecer en forma de pena, que es lo que permite estabilizar la norma e impedir que la sociedad se convierta en una selva sin reglas.

Pero para ir a tono con la terminología imperante, ¿cuál sería el bien jurídico que protege la tipificación del grooming como conducta que debe ser marginalizada comunicativamente?

En España, para el año 1948 se empezó a tipificar ciertas conductas conocidas como "delitos contra la honestidad", figura nada acertada al crear, como ya lo hemos sostenido, un escenario de impresentable inseguridad jurídica al tratarse de un bien jurídico poco sustentable, como posteriormente se vio. Este error conceptual duró

36 Dolz Lago, M. "Un acercamiento al nuevo delito de child grooming. Entre los delitos de pederastia", Diario La Ley, n. ${ }^{\circ} 7575$, p. 1740.

37 Jakobs, Gunther. La imputación objetiva en Derecho penal, Manuel Cancio Meliá (trad.) y estudio preliminar de Carlos Suárez González y Manuel Cancio Meliá, Madrid, 1996, pp. 83-84. 
hasta la reforma de 1989, en la que se recogió lo dictado por la doctrina mayoritaria y jurisprudencia. Si de definiciones hablamos, González Gascón, Ramos Vázquez o el mismísimo Cancio Meliá prefieren la expresión "acoso por medio de las tecnologías de la información"; Díaz Cortés se inclina por la expresión “contacto TIC preordenado a la actividad sexual con menores" y en la jurisprudencia se pueden llegar a encontrar otras denominaciones como "corrupción de menores de trece años a través de tecnologías de la información y la comunicación" 38 o "delito de abuso sexual a través de Internet" 39 ; pero, en todo caso, debe quedarnos claro que si deseamos hablar de "bien jurídico protegido" en estos casos sería la indemnidad sexual del menor y así lo hizo España, mediante la Ley Orgánica 3/1989, del 21 de junio; se modificó lo relativo a la honestidad por libertad sexual, eliminando cualquier utilización de lo moral en relación con la calificación de honestidad. Cuenca Padilla, en esa línea, concluye acertadamente en nuestra opinión que "la protección de la libertad sexual por parte del Derecho Penal manifiesta una concepción de la sexualidad y de la especial trascendencia que se le da en relación con el desarrollo personal, pero sirve como forma de delimitar el espacio de actuación del Derecho Penal"40.

\section{SOBRE EL SUJETO ACTIVO}

El sujeto activo debe ser por regla general un adulto. Con esto evitamos abrir un abanico histérico de castigos que afectaría a un menor de 14 años que practica sexting con su novia de la misma edad. Desde nuestra óptica, los menores solo pueden ser considerados sujetos activos en el grooming si tienen más de 16 años y la víctima es menor que él al menos con tres de diferencia. España y Estados Unidos no lo consideran así, con lo cual han inaugurado una caza de brujas en pleno siglo XXI, no obstante legislaciones como la del Reino Unido plantean claramente como sujeto activo al adulto y al mayor de 16. En el caso español, encontramos dificultades generadas por lagunas o anomias en la redacción, pues de la lectura del segundo párrafo del 183 ter se desprende un castigo al sexting o intercambio de contenidos pornográficos de menores con otro menor de dieciséis años, siendo exigido como elemento objetivo que el menor contactado remita en los chats imágenes de pornografía de menores. La pregunta que surge es ¿qué sucede si el menor contactado tiene 13 años y, manipulado emocionalmente por otro de 17 , decide enviarle fotos de desnudos pero que corresponden a otro niño de 12 años? Pues siguiendo la línea de lo prescrito en el artículo 189 del Código Penal español, ambos serían considerados autores de pornografía infantil,

38 Vid. sentencia Audiencia Provincial de Barcelona, 19.07.2013.

39 Hortal Ibarra, J. C. "El nuevo delito de 'online child grooming' (art. 183 bis CP): ¿otro ejemplo de cirugía preventiva aplicable a la legislación penal?”, en Garantías constitucionales y Derecho penal europeo (dir. Mir Puig, Corco y Bidasolo; coord.: Gómez Martín), Marcial Pons, 2012. En concreto cita la SAP, Cádiz, 14.05.2012.

40 Cuenca Padilla, A. (2014). El nuevo delito de grooming del artículo 183 bis del Código Penal (trabajo fin de grado), Universidad Autónoma de Barcelona. 
lo cual nos conduciría al absurdo de castigar como autor a la víctima por la ausencia de delimitantes, de fronteras claras en el tipo.

\section{SOBRE EL SUJETO PASIVO}

Sobre el sujeto pasivo también se generan discusiones, y esto va a depender de la edad de consentimiento sexual de cada legislación. Un breve repaso en Europa nos lleva a descubrir marcadas diferencias entre sus estados. Por ejemplo, mientras en Malta la edad de consentimiento sexual se alcanza a los 18 años y antes de ella cualquier contacto sexual de un adulto con un menor a esa marca se considera abuso sexual, en Portugal, Hungría, Alemania, Austria e Italia se considera que a los 14 años un ser humano ya puede dar vía libre a intercambios lúbricos. Finlandia, Francia e Irlanda se inclinan por declarar legal el contacto sexual consensuado con personas desde que cumplen los 17 años, mientras Letonia, Lituania y Luxemburgo manejan el tope de 16 años.

En Sudamérica, Ecuador por ejemplo, maneja la misma tesis de Malta, en el sentido de castigar a todo adulto que mantenga contacto sexual con un menor; ciertamente se hacen distinciones de pena entre los menores con edades por debajo de los 14 y los que se encuentran entre esa edad y los 18 años. Así el artículo 167 de su Código Penal prescribe: "La persona mayor de dieciocho años que recurriendo al engaño tenga relaciones sexuales con otra, mayor de catorce y menor de dieciocho años, será sancionada con pena privativa de libertad de uno a tres años". En todo caso, queda claro que si lo que se protege es la indemnidad sexual de los menores, estos, con las diversas connotaciones de cada legislación en cuanto a la edad del consentimiento sexual, son siempre el sujeto pasivo.

\section{SOBRE EL ANTICIPO DE PUNIBILIDAD AL PEDERASTA DIGITAL}

Luhmann, que no es, a diferencia de la repetida tesis, el precursor filosófico de Jakobs, nos dice que el "concepto de riesgo se refiere a la posibilidad de daños futuros debido a decisiones particulares que se toman en el presente (decisiones que son tomadas sin tener consciencia de lo que sucederá en el porvenir), por consiguiente, es una forma para realizar descripciones presentes del futuro desde el punto de vista de que uno puede decidirse, en atención a los riesgos, por una alternativa u otra" ${ }^{41}$. Partiendo de este entendimiento y recogiendo que reconocidas investigadoras como Ana Salter entienden al grooming como "seducción emocional" 42 y Sylvia Kierkegaard

41 Luhmann, Niklas. Complejidad y modernidad. De la unidad a la diferencia, Josetxo Beriain y José María García Blanco (trads.), Madrid, Trotta, 1998, p. 163.

42 Salter, A. Transforming Trauma: A Guide to Understanding and Treating Adult Survivors of Child Sexual Abuse. Sage: Thousand Oaks, CA, 1995; Wilcox, Richards y O'Keeffe. "Resilience and Risk Factors Associated with Experiencing Childhood Sexual Abuse", en Child Abuse Review, vol. 13, 2004, pp. 338-352, disponible en [www.interscience.wiley.com], DOI: 10.1002/car.862. 
lo conceptualiza como "una estrategia utilizada por potenciales abusadores para seducir a los niños y conseguir que realicen conductas sexuales" 43 , queda claro que la tipificación del grooming se fundamenta en la necesidad de la marginalización comunicativa explicada por Jakobs, lo cual nos lleva indefectiblemente al adelantamiento de los dispositivos de castigo.

Pero ¿por qué castigar así?, ¿es válido argumentar que dado que han causado un mal, es preciso adjudicarle al autor otro de similar calado?

No, la pena (y el anticipo de punibilidad constituye una forma de ésta) no se reduce a provocar un daño en función de un mal ya causado, porque de ser así el derecho penal quedaría vaciado de justificación si se desarrollara a partir de una premisa tan grosera e irracional. El anticipo de punibilidad tiene como eje la estabilización de la norma que se pretende lesionar con base en la fundada presunción o verificación según registros judiciales de que el autor ya ha cometido previamente delitos graves, por consiguiente se trata de conservar la vigencia de la norma a costa de un sujeto plenamente responsable en derecho ${ }^{44}$.

Es sorprendente el creciente número de autores que, con diversos ejes argumentativos, sostienen que no hay delito hasta cuando se produzca el encuentro. Paradigmático en esta sede es el núcleo dogmático que rodea a la legislación española respecto de este delito. El profesor Muñoz Conde hace la siguiente reflexión al artículo 183.bis del Código Penal español: “[...] requiriendo el acercamiento no siempre es fácil determinar hasta qué punto ese acercamiento se hace realmente para cometer alguno de los delitos descritos en el propio precepto" 45 . En realidad esta posición no satisface, desde el entendimiento, que un niño es heteroadministrado, y más cuando se trata de un menor que sufre maltratos, matoneo o se siente simplemente ignorado por sus padres o tutores, es evidente que no cuenta con los fundamentos elementales para entender qué es lo que busca un adulto en él.

Insistimos: ¿No sería lógico que un adulto busque a sus pares si desea conversar?, ¿por qué no visita un pub o un club nocturno?, ¿conversa con un niño y le inquiere sobre su vida porque está haciendo una investigación académica?, ¿con la autorización de quién?, ¿le habla de encuentros para jugar ajedrez o hablar del último libro de Naomi Klein?

Ya Kant nos advirtió en su Metaphysik der Sitten que A, B, C, D y un interminable etcétera pueden pedirles a los otros que suscriban, simbólicamente por supuesto,

43 Kierkegaard, S. "Cybering, Online Grooming and Ageplay", Computer Law and Security Report, 41, 2008, p. 22, disponible en [www.sciencedirect.com/science/article/abs/pii/S0267364907001136].

44 Jakobs, Gunther. Derecho penal, cit., p. 9. También Luhmann, Niklas. Ökologische Kommunikation Kann die moderne Gesellschaft sich auf ökologische Gefährdungen einstellen?, pp. 153 y ss.

45 Muñoz Conde, Derecho Penal. Parte Especial, 8. a ed., Valencia, Tirant lo Blanch, 2010, p. 241. 
un pacto civil para garantizar la paz social. De modo tal que usted renuncia a cierta parte de su libertad para no afectar ninguna esfera ajena, y espera de los demás que se comprometan en idéntico modo. Pero el mismo Kant nos plantea una interesantísima reflexión, bastante olvidada en las facultades de Derecho actuales, cuando nos pregunta: ¿Qué hacemos con esos sujetos que, pese a ser invitados, no desean someterse a ninguna constitución civil? La respuesta nos la da en otra de sus obras, Zum ewigen Frieden ${ }^{46}$, dejando una frase que sin duda suena muy dura: si no quiere someterse al pacto, "hay que separarse de él" 47.

Ahora bien: el mismo Muñoz Conde continúa su análisis al previamente referido 183. bis del punitivo español, cuya redacción parece haber sido realizada por los propios victimarios y concluye que "sólo es punible en relación con algún delito de agresión sexual o abuso sexual, o de utilización del menor para espectáculos exhibicionistas o pornográficos; por tanto, el hecho, por ejemplo, de captar la imagen del menor posando desnudo o en una postura o actividad inequívocamente sexual, o la voz del menor en una conversación de contenido sexual a través de un teléfono móvil o de internet por parte de un adulto, simplemente para la propia satisfacción, sin después llegar al contacto físico ni difundir su imagen por Internet, ni mostrarla a otras personas no entra dentro del tipo previsto en el artículo 183.bis"48.

Claro que este aserto es difícil de asimilar por un derecho penal realista. Jakobs se vale de una cita de Fitche: "[Q]uien abandona el contrato ciudadano en un punto en el que en el contrato se contaba con su prudencia, sea de modo voluntario o por imprevisión, en sentido estricto pierde todos sus derechos como ciudadano y como ser humano, y pasa a un estado de ausencia completa de derechos"49; y agrega otra de Rousseau que es radical respecto del que delinque al punto de desconcertar e infundir miedo en todos los demás, señalando que a éste se le debe neutralizar "más como enemigo que como ciudadano" para -entre otros fundados argumentos- dejar en evidencia la necesidad actual de anticipar la barrera de punibilidad para enfrentar azotes criminales que son idénticos a una pandemia de incalculables costes si no se toman medidas oportunas.

Entonces, ¿se debe castigar en la fase previa a la lesión de un bien jurídico?

Pues la tendencia inicial frente a esta interrogante es oponerse. Que eso sería apoyar un derecho penal de autor y que el derecho penal de garantías castiga a la persona por lo que hace y no por lo que parece y lo tenemos claro. No existe la más remota posibilidad de discusión en este punto.

46 Kant, I. Sobre la paz perpetua, Kimana Zulueta (trad.), Madrid, Ediciones Akal, 2011.

47 En el mismo libro, segunda parte, nota 1.

48 Muñoz Conde, Derecho Penal..., cit., p. 241.

49 Jakobs, Günther y Cancio Meliá, M. Ob. cit., p. 2. 
Lo que propone el normativismo normativo sistémico es legislar de acuerdo al desarrollo social, porque el derecho penal es hijo de su tiempo. Hoy asistimos a fenómenos delictivos cada vez más atroces auspiciados por la globalización. Existen grupos terroristas que lejos de actuar mundialmente al margen de la ley son financiados y protegidos por países que se disfrazan ante la comunidad planetaria como respetuosos de la coexistencia pacífica.

¿Cómo enfrentar a criminales que hablan todas las lenguas imaginables, que pese a haber nacido en países centrales odian a sus congéneres por haber succionado desde su nacimiento el credo del odio sin mediar motivos, que forman parte de organizaciones que cuentan con mayores recursos económicos que todo el producto interno bruto de Bolivia, Haití o Ecuador y que en cualquier momento con enormes facilidades secuestran aviones, los estrellan contra edificios llenos de seres humanos, hacen explotar un estadio o un centro comercial en horas de la mayor afluencia posible de personas?

Como referíamos ut supra, leemos fundamentaciones de altísimo nivel científico contra el normativismo sistémico pero todavía no logran solucionar el problema de la cimentación cognitiva de una pena devaluada porque solo aparece post factum, esto es, mientras una niña llora viendo cómo su mundo se derrumba ante el ataque de un pederasta, como en el caso de Amanda. El anticipo de punibilidad es absolutamente necesario y justificado cuando se trata de desbaratar aparatos criminales con gran poder para erosionar la sociedad. A esta gente hay que capturarla sin temor durante los actos preparatorios y esto es así porque este tipo de sujetos ya han dejado de ser personas y su neutralización ex ante factum es perfectamente compatible con un verdadero Estado de derecho que privilegia a los decentes, a los pacíficos, a los que se comportan fieles al derecho.

Tenemos claro que un derecho penal del enemigo solo se puede legitimar en situaciones extremas, de modo marcadamente excepcional ${ }^{50}$. Cuando asumimos el drama de menores víctimas de abuso sexual desde las víctimas se comprende con otras coordenadas la conocida frase de Jakobs "aumentando las penas, limitando las garantías, el Estado no habla con sus ciudadanos, sino que amenaza a sus enemigos" 51 , que encontramos generalmente descontextualizada porque el derecho penal del enemigo debe utilizarse solo en casos excepcionales, cuando el Estado es incapaz - con su esquema de derecho penal del ciudadano- de neutralizar a cierto tipo de criminales como las actuales organizaciones transnacionales de pornografía infantil y pederastia. Ante un escenario en el que atentar contra la indemnidad sexual

50 Jakobs, Günther. "La ciencia del derecho penal ante las exigencias del presente", en Dogmática de derecho penal y la configuración normativa de la sociedad, Teresa Manso (trad.), Madrid, Civitas, 2004, pp. 27-50.

51 Jakobs, Günther. La ciencia, cit., p. 44. 
de niños se convierte en un delito reiterado, en el que las fuerzas policiales están limitadas por un exceso de barreras, lo primero que debe hacer la sociedad es pensar seriamente si desea mantenerse como comunidad o por el contrario se disuelve formalmente y pasamos a deambular por un universo apocalíptico como el que nos presenta un film de Mad Max.

Cuando se captura un potencial pederasta digital es nuclear someterlo a intensos interrogatorios a partir de los cuales el Estado pueda obtener datos claves para desbaratar a la red de violadores y finalmente, luego de ser procesados y en caso de ser hallados responsables, mantenerlos en prisión hasta el final de sus días, porque este tipo de criminales tienen derecho a seguir vivos, a ser alimentados, a tener espacios de recreación, a no ser torturados, pero la pena no es un boleto a Disney World, la pena es lo que es y no lo que el criminal quiere que sea. Pero así como tienen derechos, dado que la despersonalización es parcial al producirse parcialmente una despersonalización, no es posible que vuelvan a deambular por las calles por las razones ya suficientemente expuestas en líneas previas y sobre las que se profundizará más adelante.

\section{0. ¿POR QUÉ APLICAR LA SICHERUNGSVERWAHRUNG O CUSTODIA DE SEGURIDAD A LOS PEDERASTAS?}

Imagine a un pederasta que ingresa a un centro carcelario cuando ha cumplido 22 años y es condenado a 20 años de privación de su libertad; al salir de prisión estará en condiciones físicas de tener una erección, de dañar a otros menores. La solución no es la castración química y no nos brinda una solución adecuada sencillamente porque un pederasta que no puede penetrar a su víctima con su órgano sexual no tardará en encontrar un objeto que sustituya el falo. Generará el mismo efecto nocivo en la sociedad. Lo correcto es aplicarle una custodia de seguridad, lo cual significa decirle, el día en que va a salir en libertad y mientras organiza sus cosas para volver a la calle, que no se cambie de ropa, porque se va a quedar allí, bajo vigilancia del Estado, haciéndole entender que es por la seguridad de los demás pero también por la suya, pues el riesgo de que sea eliminado en el exterior es altamente probable tomando en consideración que con sus conductas no ha generado precisamente simpatías.

Y es que son muchos los casos en los que la pena simplemente no basta para lograr el fin de la prevención especial, por la sencilla y probada circunstancia de que existen delincuentes, esencialmente en el ámbito de los delitos contra la integridad sexual y en la esfera de las violaciones a la libertad de los demás, que presentan perfiles criminológicos mucho más resistentes a la rehabilitación social que otros infractores. La sicherungsverwahrung o custodia de seguridad propia del derecho alemán declara que su propósito es lograr la reinserción del delincuente a la sociedad; no obstante, como bien lo refieren autores de la talla de Jeschek y Weingend, "el problema de esta medida reside en que la misma está destinada con un objetivo asegurativo, 
palabras más, palabras menos, a la simple reclusión del infractor"52. Monstruosos y recurrentes crímenes sexuales obligaron a los alemanes a aplicar la custodia de seguridad. Para ellos no es algo nuevo. Bastaría recordar que apareció regulada en el sistema punitivo germano el 24 de noviembre de 1933 con la conocida Gesetz gegen gefährliche gewohnheitsverbrecher und über Massegeln der Sicherung und Besserung. Ciertamente, como nos refiere en una magnífica monografía Boguñá Nieto, desde 1933, esta ley ha tenido una serie de modificaciones vía reforma en 1998, en el 2002 y una última en el $2004^{[53]}$. Ahora bien: una breve revisión del artículo 129 de la Ley Penitenciaria de Alemania, vigente, actual, nos deja el tema aclarado. No nos miente. La esencia de la custodia es la custodia segura del sujeto peligroso para garantizarle tranquilidad a la sociedad, no obstante que en ningún punto deja de mencionar que se sigue apostando, haciendo grandes esfuerzos por tratar de rehabilitar a estos individuos pese a su manifiesto deseo de estar al margen de la civilidad.

\section{NO SON SIMPLES ACTOS PREPARATORIOS}

Hay quienes "se han apartado probablemente de manera duradera, al menos de modo decidido, del Derecho, es decir, que no prestan la garantía cognitiva mínima que es necesaria para el tratamiento como persona" 54 , se trata de seres que nos amenazan en razón de su statu iniusto y en estos casos se justifica equiparar cualquier acto previo al resultado dañino integral porque la pena está orientada al aseguramiento de hechos futuros más que a un mero castigo por lo efectivamente generado.

Ya en el momento de la búsqueda del adulto a un niño en internet para forjar una "amistad" con tintes sexuales, en todo contacto del adulto con un niño en la búsqueda de conversaciones de corte erótico o sexual existe un fenómeno criminal, no se trata de simples actos preparatorios sino ya de un delito como tal; solicitarle fotos desnudo o captarlo en secuencias decididamente sexuales además de constituir grooming abre las reglas concursales para la acumulación de penas pues -no admite disenso- estamos también frente a casos de pornografía infantil, por ejemplo, siendo este paso solo la lógica estación de partida de ese ferrocarril del dolor.

Estamos ante un delito de peligro abstracto, siendo indiferente que haya una lesión física a través del contacto, dado que el simple hecho de que un adulto ingrese a la red, distorsione su verdadera identidad, busque a niños para mantener relaciones de

52 Cfr. Jescheck, Hans Heinrich. Lehrbuch des Strafrechts: allgemeiner Teil, cit., pp. 813-814, citado en Cano Paños, M. A. El marco jurídico y criminológico de la custodia de seguridad en el derecho penal alemán, Cuadernos de Política Criminal, n. ${ }^{\circ}$ 91, pp. 205-250, la referencia es tomada de la página 207.

53 Boguñá Nieto, Marta. La custodia de seguridad, 3 cuestiones fundamentales, tesis de grado de derecho de la Universidad Pompeu Fabra, Barcelona, 2013, disponible en [https://repositori.upf.edu/bitstream/ handle/10230/23435/TFGDRET_Bogu\%C3\%B1a_2012_2013.pdf?sequence=1\&isAllowed=y].

54 Jakobs, Günther y Cancio Meliá, M. Ob. cit., p. 40. 
supuesta amistad, indague sobre su vida, le solicite datos de sus padres, tiene un tratamiento penal y el momento en que solicita audios, fotos, sugiera o no encuentros, ya implica una conducta criminosa perfectamente subsumible a esta moderna figura dentro del amplio espectro del abuso sexual infantil. Jakobs nos alerta sobre la peligrosa ilusión que nos invade hoy, cuando seguimos aferrados a la caduca creencia en la que estamos vinculados al derecho y así todos nos vamos a someter a un orden determinado, nos dice que esto no pasa de ser "una cómoda ilusión" 55 , dado que un sistema jurídico, por más positivizado que esté, si no tiene un auditorium dispuesto a respetarlo no tiene ninguna validez práctica. En el terrorismo, como en la delincuencia organizada trasnacional y en la pederastia con su amplio espectro de conductas macabras, estamos frente a criminales que por un lado pretenden atentar contra el edificio que alberga a la configuración normativa de la sociedad, pero por otro lado exigen, al ser procesados o capturados, un trato reservado para las personas que se comportan en derecho. Esperar que se consideren actos preparatorios y no delitos consumados, el hecho de estar diseñando y armando un artefacto explosivo para hacerlo detonar en un centro comercial lleno de gente que nada tiene que ver con las ideas justificadas o no de los implicados o mantener un cruce epistolar lúbrico, erótico o sexual con un niño, es decididamente inaceptable. La pena para todos estos individuos debe ser entendida como coacción, como respuesta firme del Estado a que el acto comunicativo de estos delincuentes no tiene el más remoto valor para derrumbar la vigencia de la norma. Ergo, el contacto con menores a través de medios telemáticos del que se desprende preparación para causar daño es una desviación punible, que en el concreto ámbito del efecto preventivo-especial de aseguramiento de la pena privativa de libertad, nace del convencimiento de que el responsable es un alarmante foco de peligro social, y ciertamente para ir a tono con el principio de legalidad, conviene distinguir entre los actos preparatorios y el delito consumado, lo cual en el caso del grooming es siempre lo segundo. En razón del efecto asegurador respecto de potenciales hechos futuros, el Estado debe estar un paso delante de ciertos delincuentes, como los pederastas. Debe quedarle claro al legislador que no se debe esperar a que el minotauro digital cite a una cena con velas al niño ni que tenga relaciones sexuales con el menor para que se verifique la desviación punible. Esto es otro tipo penal, sería, además de grooming, violación, por supuesto, que no se necesita una laurea en jurisprudencia ni en criminología para entender perfectamente que aquí hay una conducta criminal que lesiona gravemente la indemnidad de un ser humano que recién está comenzando a vivir. Es tarea del legislador comprender algo muy básico que nos ha enseñado el profesor Jakobs en materia penal: "Una norma también rige cuando es infringida, ya el mero hecho de que la infracción de la norma es denominada como tal es un caso evidente de la vigencia de la misma"56.

55 Jakobs, Günther y Cancio Meliá, M. Ob. cit., p. 13.

56 Jakobs, Günther. ¿Cómo protege el derecho penal y qué es lo que protege?”, en El pensamiento filosófico y jurídico-penal de Gunther Jakobs, Carlos Daza (ed.), 1.a ed., México, Flores Distribuidor, 2007, p. 6. 
En ese orden de ideas, se parte de conceptos tan elementales como el de tomar a la víctima como un ente libre pero siempre en un estadio meramente declarativo porque nunca es libre. El delincuente que lo acecha sí lo es y lo ataca desprevenido para despojarlo de sus bienes, atentar contra su integridad sexual o arrancarle la vida. Para tratar de emparejar esta relación abiertamente asimétrica, el derecho debe intervenir seriamente. El verdadero desarrollo de un niño que necesita estar lejos de la carga contaminante de los que ya no somos inocentes es una quimera en sociedades como las actuales, porque el bienestar no crece contrafácticamente. Si el mensaje que se les envía a sujetos dispuestos a lesionar niños es que pueden hacer un catálogo innumerable de acciones como dialogar románticamente con un menor con el disfraz de ser su igual y no serán castigados hasta cuando "soliciten" un encuentro, estamos ante un monumental desprecio a la norma primaria. Si esta dice que no debemos matar, no debemos estafar, ni abusar sexualmente de nuestros congéneres, y sin embargo dejamos un gran segmento de criminalidad sin penar, el resultado no es otro que el vaciamiento total de sentido de la configuración social como tal.

\section{EL CASO CHILENO}

Chile debatió durante tres años la pertinencia de castigar al child grooming o no. Si bien los legisladores que llevaron adelante el proyecto hasta su normativización en la Ley 20.256 siempre sostuvieron estar influenciados por la legislación australiana, en la que el grooming se castiga con 15 años de cárcel, lo cierto es que las penas en el caso chileno no pasan de cinco años ${ }^{57}$. Particularmente oscuro resulta identificar el bien jurídico que pretende proteger la legislación chilena, pues hace referencia a cuestiones de moralidad o pudor público que según autores como Garrido podrían deducirse como aspectos constitutivos de la pornografía infantil, lo cual nos plantearía serios problemas al momento de la imputación objetiva, pues no cabe duda de que se trata de conceptos estridentemente subjetivos. Esto produce inseguridad jurídica, pues nos conduce a interpretaciones antojadizas. Ya hemos dejado referido que la doctrina mayoritaria encuentra consenso en el sentido de que el bien jurídico protegido es la indemnidad sexual y la salud mental del menor. El profesor Suárez Mira, enfocado en el caso español, nos dirá que plantear la moral o la honestidad como el bien jurídico a protegerse frente a este tipo de conductas es equivocado pues resulta "inimaginable interpretar literalmente el término honestidad como alusivo al honor, decoro o moral sexuales, el cual además presentaba algún inconveniente de calado. Así, de entender que era la honestidad el objeto de protección, se llegaría a considerar atípicas las conductas que recayeran sobre persona reputada socialmente

57 Scheechler, Christian. “Aspectos fenomenológicos y políticos-criminales del sexting. Aproximación a su tratamiento a la luz del Código Penal chileno", en Política criminal, vol. 14, n. ${ }^{\circ} 27$, Santiago, 2019 , disponible en [file://C:/Users/glori/Downloads/Vov114N27A11\%20(2).pdf] (consulta: 7 de junio de 2019; Garrido Montt, Mario, Derecho Penal, Parte Especial, tomo III, Santiago, Editorial Jurídica de Chile, 2002, p. 417. 
deshonesta, o incluso sobre persona respecto de la cual el calificativo de honesta resultara impropio, como es el caso de los niños de corta edad"58. Por otro lado, en el caso chileno se sancionan las conductas en un contexto lúbrico como las del niño actuando en un teatro sexual novelado o usando su registro sonoro con oraciones dirigidas a un auditorium sexual. Queda fuera del tipo de su artículo 366, por ejemplo, el uso de la voz del niño obtenida en el contexto de un diálogo aparentemente neutro que luego es utilizada por el adulto en montajes de audio y video con contenido lúbrico.

\section{EL CASO ECUATORIANO}

Ecuador es uno de los 62 países que hasta la fecha sancionan el grooming, aunque lo hace de modo muy tibio considerando que, según datos de la propia Fiscalía General del Estado, entre enero y abril de 2019 se denunciaron 52 casos, lo cual equivale a más de una docena por mes, 13 mensuales para ser exactos. La cifra, curiosamente, se dispara entre 2017 y 2018, cuando se recibieron 380 denuncias. No obstante, estos datos engañan. Bastaría señalar que de enero de 2017 a noviembre de 2018 ingresaron 13.000 denuncias por abuso sexual con víctimas entre los 4 y 17 años de edad. Tres de cada mil niños en Ecuador han sido víctimas de pederastia, según estos reportes oficiales. Sin embargo, estos datos no reflejan la realidad. No se tienen en cuenta ni remotamente los miles de casos que no llegan a judicializarse por diversos factores como temor a los perpetradores, la extrema pobreza, ignorancia de las víctimas y la escasa credibilidad en un poder judicial que sucumbe en medio de escándalos de todo tipo.

¿Qué nos dice el Código Orgánico Integral Penal ecuatoriano respecto de este delito?

Pues bien, lo tipifica y reprime en tres supuestos, con penas diversas, en el artículo 173, cuyo tenor literal expresa:

Artículo 173. Contacto con finalidad sexual con menores de dieciocho años por medios electrónicos. La persona que a través de un medio electrónico o telemático proponga concertar un encuentro con una persona menor de dieciocho años, siempre que tal propuesta se acompañe de actos materiales encaminados al acercamiento con finalidad sexual o erótica, será sancionada con pena privativa de libertad de uno a tres años.

Cuando el acercamiento se obtenga mediante coacción o intimidación, será sancionada con pena privativa de libertad de tres a cinco años.

La persona que suplantando la identidad de un tercero o mediante el uso de una identidad falsa por medios electrónicos o telemáticos, establezca comunicaciones

58 Suárez-Mira Rodríguez, C. Los delitos de agresiones y abusos sexuales contra menores. Madrid, Biblioteca Nueva, 2002, p. 42. 
de contenido sexual o erótico con una persona menor de dieciocho años o con discapacidad, será sancionada con pena privativa de libertad de tres a cinco años.

Es interesante advertir que el legislador ecuatoriano naufraga en una laguna de imprecisiones en esta definición. Si bien ha entendido adecuadamente que el tipo no exige que los contactos o las solicitudes sexuales de adultos a niños sean repetidos ni secuenciados, que es la tesis que enarbolan aquellos juristas que subsumen al grooming simplemente como una esquirla del $\operatorname{acoso}^{59}$ dado que, en la mayoría de los casos, las búsquedas, los chats, los pedidos son histéricamente repetidos por el pederasta, basta con un solo acto de solicitud sexual para que el crimen se materialice. Por otro lado, el marco penal ecuatoriano presenta deficiencias muy similares a las de la redacción peruana, pues siguiendo el principio de legalidad, no podríamos sancionar a un adulto que contacta a un niño y mantiene una relación prolongada con este, pues mientras no “proponga concertar un encuentro" no cabe castigo. Si le pide fotos, audios o videos al niño tampoco podríamos sentenciarlo porque tenemos un penoso vacío normativo.

Es meridiano que, siguiendo la ruta trazada por la Directiva 2011/92 del Parlamento Europeo, se exija la concurrencia de un principio de ejecución. Luego, el artículo en análisis se refiere a "la persona que", sin especificar la edad del agente activo en el delito. Se debió establecer claramente que debe tratarse siempre de un adulto. De lo contrario, caemos en la penosa caza de brujas de la legislación estadounidense, que sanciona los contactos digitales entre niños de edades similares, lo cual implicaría negar las interacciones infantiles y juveniles actuales. Para evitar además que casos de adolescentes que contactan niños para fines sexuales queden impunes, en el mismo artículo se debió definir que siempre que medie una diferencia de edad de dos años entre autor y víctima, se castigará con una pena X. Nótese, además, que la legislación ecuatoriana utiliza el verbo 'proponer' mientras tratados europeos como el Convenio de Lanzarote, cuya denominación oficial es Convenio del Consejo de Europa para la protección de los niños contra la explotación y el abuso sexual infantil, del 25 de octubre de 2007, gira en torno al verbo 'solicitar', lo cual se verifica fácilmente al revisar el artículo 23, en el que claramente se tipifica la "solicitation of children for sexual purposes". 'Solicitar' también es el verbo rector por el que se decanta la Directiva 2011/93/UE, del 13 de diciembre de 2011, relativa a la lucha contra los abusos sexuales y la explotación sexual de los menores y la pornografía infantil.

¿Es importante detenernos a analizar cuestiones que podrían considerarse meramente semánticas?

Sin duda alguna que sí, porque el principio de legalidad o nos lo creemos o no nos lo creemos, pero no lo podemos estirar como nos convenga. El verbo 'proponer' 
implica exponer un proyecto o una idea a otra persona para que esta lo acepte y dé su conformidad para realizarlo mientras el transitivo solicitar, derivado del latín sollicitāre, implica pretender, pedir o buscar algo. En consonancia con lo apenas referido, en el primer caso es punible la acción de presentarle al niño un proyecto sexual, y en el segundo, debe concretarse la petición de favores sexuales para que la conducta del adulto sea punible. Nada se dice del contexto previo en ninguno de los dos escenarios.

Para concluir, en este apartado, es interesante advertir que en el caso ecuatoriano las penas plantean un piso y un techo, empiezan con penas de un año en el primer supuesto y tres años en los dos incisos posteriores, pero ninguno de los tres supuestos excede la barrera de los cinco años, lo cual les permite a estos focos de peligro solicitar la suspensión condicional de la pena, que fácilmente, en medio de un modelo de administración de justicia seriamente cuestionado, pueden obtener, con lo cual el foco de peligro queda liberado, exactamente igual a lanzar una antorcha a un bosque virgen en el verano y esperar que no se produzca un incendio forestal.

\section{EL CASO PERUANO}

En Perú los datos sobre violencia sexual son alarmantes. En la exposición de motivos de la ley 30171 se señala que el $76 \%$ de las víctimas son niños, lo cual es confirmado por el estudio realizado por el Programa de Investigaciones Criminológicas y Análisis Prospectivo del Ministerio Público, que abarca el periodo 2013-2017, que solo se denuncia el $48 \%$ de los casos, mientras que el resto queda en la más ignominiosa impunidad. De los casos denunciados, el $90 \%$ no llega a sentencia condenatoria. En este caótico escenario, el 27 de septiembre de 2013 se expidió la Ley 30096, también conocida como Ley de Delitos Informáticos, en cuyo capítulo III se establecen (artículo 5) sanciones para los actos relativos a proposiciones a niños, niñas y adolescentes con fines sexuales por medios tecnológicos bajo esta descripción:

El que, a través de las tecnologías de la información o de la comunicación, contacta con un menor de catorce años para solicitar u obtener de él material pornográfico, o para llevar a cabo actividades sexuales con él, será reprimido con pena privativa de libertad no menor de cuatro ni mayor de ocho años e inhabilitación conforme a los numerales 1, 2 y 4 del artículo 36 del Código Penal. Cuando la víctima tiene entre catorce y menos de dieciocho años de edad y medie engaño, la pena será no menor de tres ni mayor de seis años e inhabilitación conforme a los numerales 1,2 y 4 del artículo 36 del Código Penal.

La redacción del artículo es confusa, pues impide sancionar de manera efectiva a los infractores, dado que no brinda un marco de protección adecuado al menor, no enfoca los actos de contactar a un menor para mantener conversaciones o relatos con contenido sexual a través de medios de comunicación, redes sociales y análogos. 
Como vemos, solo se sanciona al pederasta si es que pide u obtiene material pornográfico del niño, o si se lleva adelante actos relativos a un encuentro sexual. No obstante, ya el mero acercamiento por parte de un adulto a un menor, con la intención de generar una relación con este, pidiendo datos sobre su vida, manipulándolo para hacerle creer que están en una situación de igualdad, es constitutivo de desviación punible. Podemos discutir si se trata de un delito tentado pero no existe duda sobre su configuración.

\section{EL CASO COLOMBIANO}

En el caso colombiano, en el año 2014 se presentaron 26 denuncias por grooming. Para el 2015 la cifra subió a 44 requerimientos de investigación, en 2016 se presentaron 69 denuncias ${ }^{60}$ pero no obstante el grooming como tal no está tipificado en este país como delito. Lo más cercano de una legislación que combata a este fenómeno criminal lo encontramos en la Ley 1336 de 2009, por medio de la cual se adiciona y robustece la Ley 679 de 2001, de lucha contra la explotación, la pornografía y el turismo sexual con niños, niñas y adolescentes. Igual que la Ley 679 de 2001, aplica para la pornografía infantil y trata de personas en la red. Se objetará que los colombianos tienen una ley para combatir lo que ellos denominan "ciberdelincuencia", y ciertamente eso está tipificado y reprimido por medio de la Ley 1273 de 2009, pero en este instrumento nada se dice con relación al grooming. También es cierto que el 21 de julio de 2009 se sancionó la Ley 1336, la cual optimiza la Ley 679 de 2001. En forma específica, en su capítulo VI, sanciona los tipos penales de turismo sexual y almacenamiento e intercambio de pornografía infantil, con penas de prisión de 10 a 20 años y multas de 150 a 1500 salarios mínimos legales mensuales vigentes, pero tampoco satisface nuestra lógica exigencia de un preciso ataque a los pederastas digitales. Si bien el capítulo séptimo del libro segundo del título III del Código Penal de Colombia se titula "Delitos contra la libertad individual y otras garantías", se refiere a delitos digitales. Una revisión del mismo nos lleva a la conclusión: el artículo 192 se refiere a la violación ilícita de comunicaciones; el 193, al ofrecimiento, venta o compra de instrumento apto para interceptar la comunicación privada entre personas; el artículo 194, a la divulgación y el empleo de documentos reservados; el artículo 195, al acceso abusivo a un sistema informático; el 196, a la violación ilícita de comunicaciones o correspondencia de carácter oficial y el artículo 357 habla sobre daño en obras o elementos de los servicios de comunicaciones, energía y combustibles. Esto deja clara nuestra tesis inicial. De lo expuesto se puede ultimar que no existe como tal una ley ni norma que penalice los actos de un pederasta digital al realizar child grooming, lo que si vemos en los cuerpos punitivos de México y Argentina como se expone a continuación.

60 Centro Cibernético Policial de Colombia, Datos estadísticos de modalidades de cibercrimen no tipificadas en la Ley 1273 de 2009. Estudio de datos de los años 2014-2015. 


\section{EL CASO MEXICANO}

En el escenario penal mexicano tenemos el artículo 201 bis del Código Penal Federal, que castiga el influenciar a menores de dieciocho años a actos sexuales o a ser filmados, con o sin su consentimiento, con fines de lucro o sin ellos, esto con el fin de realizar pornografía infantil, e impone penas de hasta tres mil días de multa y hasta dieciséis años de cárcel. Usar las redes sociales o mediante encuentros físicos para influenciar a menores de edad a participar de filmaciones pornográficas ilegales. El grooming existe, como es lógico, incluso con la aceptación del menor de edad, dado que este no es capaz de dar su consentimiento. En el artículo 202 del mismo cuerpo legal se señala que comete el delito de pornografía infantil o de personas que no tienen capacidad para comprender el significado del hecho o de personas que no tienen capacidad para resistirlo quien procure, obligue, facilite o induzca, por cualquier medio, a una o varias de estas personas a realizar actos sexuales. El legislador mexicano entiende que el grooming es la herramienta usada por delincuentes para extorsionar o convencer a menores de edad de realizar este tipo de actos sexuales. Y finalmente el artículo 261 del Código Penal Federal advierte: "[...] al que, sin el propósito de llegar a la cópula, ejecute un acto sexual en una persona menor de doce años de edad o persona que no tenga la capacidad de comprender el significado del hecho o que por cualquier causa no pueda resistirlo o la obligue a ejecutarlo, se le aplicará una pena de dos a cinco años de prisión. Si se hiciere uso de la violencia física o moral, el mínimo y el máximo de la pena se aumentarán hasta en una mitad".

\section{EL CASO ARGENTINO}

En noviembre de 2013, en Argentina, la Cámara de Senadores aprobó la Ley 26904, incorporando la figura de grooming o ciberacoso sexual al artículo 131 del Código Penal. Será penado con prisión de seis meses a cuatro años el que por medio de comunicaciones electrónicas, telecomunicaciones o cualquier otra tecnología de transmisión de datos contactare a una persona menor de edad con el propósito de cometer cualquier delito contra la integridad sexual de la víctima.

\section{OTROS ESCENARIOS}

Escocia castiga con hasta diez años de prisión el encuentro con un menor de 16 años después de algunos contactos preliminares mediante internet. En esencia, castiga la reunión y no los actos preparatorios. Australia lo entiende de otro modo, sanciona hasta con 15 años de encierro al mero uso de internet para buscar actividades sexuales con menores de 16 años de edad. Ambos modelos son recogidos en la Ley de Cibercrímenes contra Menores aprobada en 2007 en Florida, que sanciona a quienes contacten con menores por internet y luego se encuentren con ellos con el fin de abusar sexualmente, penando el contacto virtual y sancionando con el máximo de la pena si llega a generar un encuentro físico. 


\section{LA CADENA DE OFENSA DEL ENEMIGO DIGITAL}

En este tipo de delitos generalmente hay cinco estaciones, por lo cual es preciso reformar nuestra legislación para permitir el anticipo de punibilidad y capturar, para su neutralización, a estos criminales antes de que la cadena de ofensa dañe más al niño, siendo que ya nos hemos referido en líneas precedentes a la cuestión de la asimetría en la relación de doble contingencia que existe entre un adulto y un niño por su condición de ente heteroadministrado, incapaz de decidir por sí mismo y urgido hasta alcanzar cierta edad, de protección.

La primera estación: El criminal contacta al niño. Lo hace generalmente a través de las redes sociales Facebook, Instagram y Tik Tok. Twitter no es una red social sino todo lo contrario, un espacio de injurias, guerras por el control político entre miles de cuentas falsas escondidas igual en el anonimato pero con otros intereses delincuenciales, por lo tanto, allí estos monstruos casi no pierden su tiempo. Una vez que la víctima es localizada, normalmente el pederasta le pide cambiar la conversación a Telegram, donde es más complicado rastrearlo por la comunicación cifrada. El pederasta siempre preferirá que el niño use un teléfono, que es más fácil de manipular y esconder que un ordenador portátil, pues éste les da mayor visión periférica a quienes están a su cargo y podrían ver con quién y sobre qué está conversando el menor.

El embaucamiento: En esta fase el depredador adapta su historia a las necesidades de la víctima, ofrece pequeños detalles de su vida imaginaria y pide al menor que le hable de su vida. Aquí es cuando recibe datos sobre padres, casa, situación social, cuidado, escuela. Si el niño tiene problemas por abandono, el pederasta le dirá que también los tiene. Si el niño es víctima de matoneo en las aulas, el pederasta le dirá que vive una situación similar y que le gustaría ayudarlo. Esta es la fase a la que más tiempo dedica, donde forja el dominio por medio de ejercicios de manipulación.

El control total de la víctima: Ya en este escalón, el pederasta empieza a requerir al menor información respecto de quién está cerca de él, trata de evitar cualquier riesgo de ser atrapado, por lo que le exige al niño que no permita que nadie toque su teléfono. Pide fotos, audios, le solicita al menor que baile, que le entregue la contraseña de sus redes sociales, reclama cuando este se atrasa para conectarse, genera una rendición de detalles milimétricos de todo lo que el menor ha hecho durante el día. Ha convencido al niño de que su relación es especial, única, que solo él puede comprenderlo y darle lo que espera de otras personas. "Cuento siempre contigo", "yo te hago los deberes", "te voy a enviar una recarga para tu teléfono", "nadie nunca nos va a separar", "amigos para siempre", son algunas de las patéticas frases que repiten.

El surgimiento del monstruo: Aquí empieza a exigir encuentros sexuales, si el niño se resiste recurre al chantaje, amenaza con mostrar a los padres de la víctima y a todos sus compañeros de la escuela las fotos o los videos que el mismo menor le ha enviado, por ejemplo. 
La estación del dolor: O'Connell nos dice en su Tipología de la cyberexplotación que en esta etapa el pederasta ya ha logrado convencer al niño de que él es su guía, una especie de ángel protector y en otros casos como un potencial "enamorado" 61 . Es aquí cuando inicia los requerimientos sexuales físicos.

\section{NOTAS ACLARATORIAS FINALES}

En líneas referidas ut supra, con una clara influencia del derecho penal del enemigo, se propone una noción descriptiva como elemento imprescindible para identificar aquellos supuestos de especial peligrosidad que no pueden recibir el mismo tratamiento que el desliz normativo que comete alguien que, por ejemplo, hurta una botella de vino en un supermercado y por lo tanto se mantiene en un status de ciudadano. Los penalistas tienen que hacer exámenes acerca de una realidad siempre dolorosa.

Siguiendo a Jakobs, el criminal, en este caso el pederasta digital, nos dice, a través de sus actos, sit venia verbo, que el mundo debe ser configurado del modo en que él se comporta, y no de otra manera. Esto equivale a un acto subversivo contra la estructura social, pues se lanza un disparo comunicacional de incalculables consecuencias: "hay que violar la norma, no respetarla", lo cual es inaceptable en civilidad.

La simple descripción de una conducta criminal como tal ya implica una marginalización en el terreno de la comunicación, ergo, el groomer debe ser perseguido por lo que efectivamente hace pero neutralizado de ser necesario, dado que es un foco que irradia peligro, con un anticipo de punibilidad. El aparato judicial debe analizar el grado de peligrosidad de este tipo de criminales considerando lo que puede hacer en el futuro para proceder a aplicarle una custodia de seguridad. Marcelino Fernández Arnaiz, con 54 años, fue liberado luego de una larga pena por pederastia, y tan solo tres días más tarde intentó violar a una niña de seis años en plena calle ${ }^{62}$.

El Estado no puede esperar a que un adulto dañe físicamente a un menor. En casos de pederastia, pornografía infantil y todo el amplio catálogo de delitos sexuales del mismo modo que en el terrorismo, se justifica la supresión o relativización de las garantías procesales porque mantener incomunicado al delincuente que generalmente opera en redes globales, intervenir sus comunicaciones, investigaciones secretas, confiscar sus bienes, allanar sus domicilios, lugares de trabajo son actos imprescindibles para poder neutralizar, con mayor probabilidad de éxito, estos fenómenos criminales.

61 O'Connell, R. A Typology of Cyberexploitation and Online Grooming Practices, Preston, Universidad de Lancashire, también en repositorio de tesis de la National Children's Advocacy Center, disponible en [http://www.jisc.ac.uk/uploaded_documents/lis_paperjprice.pdf].

62 El nivel de reincidencia de los pederastas llega a un alarmante 70\%, y estos datos los proporciona un instituto prestigioso y de credibilidad como la Clínica de Trastornos Sexuales de la Universidad Johns Hopkins. 
Decididamente, proponer la pena de muerte para este tipo de criminales es inaceptable, dejaría al Estado vaciado de fundamento para castigar. Esa no es, de ningún modo, la vía.

Lo que se plantea desde el derecho penal del enemigo es la despersonalización del infractor, de ninguna manera su impersonalización. Esto desde el entendimiento de que en toda despersonalización parcial hay parcialmente una despersonalización, lo cual nos lleva a tener claro que una vez capturado, procesado y sentenciado, el pederasta cuenta con la garantía del Estado de recibir alimentación, servicios médicos, acceso a libros, revistas, dado que lo que ha perdido es su libertad. Lo privamos solo parcialmente de medios para que vuelva a generar daño. Y es que si pretendemos privarlo de todos los medios, evidentemente estaríamos ante su eliminación física, lo cual -reiteramos- es absolutamente incompatible con cualquier sociedad mínimamente civilizada.

Una de las críticas más sólidas en torno a la tesis del derecho penal del enemigo la protagoniza Schünemann, quien rechaza que el centro del debate gire en torno al individuo como tal ${ }^{63}$. Según este destacadísimo profesor, la posición jakobsiana gira y patina sobre un eje equivocado pues lo nuclear es el diseño de dispositivos que permitan enfrentar el peligro específico derivado de desviaciones punitivas propias, por ejemplo, del crimen organizado, una amenaza que, ciertamente, exige del Estado operaciones reales para acotarlo.

Así, Schünemann se muestra partidario de ciertas reducciones a garantías propias de la legislación penal mayoritaria, las que justifica pero no por el peligro del "enemigo" sino por los fenómenos criminales como tales. Según Schünemann, "un jefe de la mafia puede ser un marido y padre que atiende las disposiciones del derecho de familia" 64 , usando este ejemplo para demostrar que Jakobs estaría decididamente equivocado cuando habla de un delincuente que se aparta permanentemente del derecho.

Ciertamente, el terrorista no camina por la calle con una camiseta de Osama Bin Laden, del mismo modo que un violador de niños puede tranquilamente (y ejemplos sobran) ser un sacerdote. Pero sus actos, por elemental lógica siempre ocultos, son secuenciados, recurrentes, y por esa razón se entienden como de desprecio absoluto a la configuración normativa de la sociedad.

Más allá de abrir un debate interesantísimo que excede las líneas del presente artículo, queda claro que lo que censura Schünemann de Jakobs no es ni el anticipo de la

63 Schünemann, Bernd. Derecho penal contemporáneo. Sistema y desarrollo. Peligro y límites, Buenos Aires, Hammurabi, 2010, p. 147.

64 Ibídem, p. 164. 
punibilidad, ni la custodia de seguridad, ni la pena como coacción, que son elementos que consideramos imprescindibles para poder combatir un fenómeno criminal, con graves tintes globales, como la pederastia digital.

No se ataca al pederasta en su rol de padre, madre, agente policial, sacerdote, piloto de avión o cajero en un supermercado. Se le combate por atentar contra la indemnidad sexual de niños; en todas sus facetas sociales, en la medida en que no haya fracturado norma alguna, tiene la garantía estatal de no ser perseguido sino amparado por el mismo acuerdo social.

¿Por qué el título del presente artículo? Pues bien, como sabemos, Minos quería convertirse en rey de Creta, y al enterarse de que el monarca previo acababa de fallecer, acudió ante Poseidón y le rogó apoyo para ganarse la simpatía de los pobladores. Ante las súplicas, Poseidón aceptó ayudarlo a entrar a Creta montando el más hermoso toro blanco, lo cual le permitirá maravillar a todos sus futuros súbditos; pero la condición era que luego de esto, el animal debía ser sacrificado. De los mares surgió el toro, y Minos logró lo que tanto deseaba, pero no cumplió su parte del trato pues sacrificó a otro bovino creyendo que podía engañar a Poseidón y escondió al que él consideraba un "regalo de los dioses". Poseidón se entera y despierta en Pasífae, mujer de Minos, una pasión sexual desenfrenada por el toro. Para consumar su unión con el animal, Pasífae solicitó ayuda de Dédalo, quien construyó una vaca de madera recubierta con piel de vaca auténtica para que ella se metiera. La bestia yació con ella. De esta unión nació el Minotauro, un monstruo con cuerpo de hombre y cabeza de toro. El Minotauro solo comía carne humana, y conforme crecía se volvía más salvaje. Cuando el monstruo se hizo incontrolable, Dédalo construyó el laberinto de Creta, una estructura gigantesca compuesta por cantidades incontables de pasillos que iban en distintas direcciones, entrecruzándose entre sí, de los cuales sólo uno conducía al centro de la estructura, donde el Minotauro fue abandonado. Minos luego invadió Atenas y los vencidos quedaron obligados a rendir un tributo a Creta. Así, una de las condiciones emergentes era entregar siete efebos (adolescentes) y siete doncellas como sacrificio para el tenebroso animal. Los catorce jóvenes eran internados en el laberinto, donde vagaban perdidos durante días hasta encontrarse con el Minotauro, sirviéndole de alimento. El monstruo devoraba a 14 menores cada cierto tiempo. Sus hijos deben conocer esta leyenda y asociarla a cualquier intento de contacto con desconocidos en internet, en la escuela, en la calle, en un parque. El Minotauro está más vigente que nunca, hay una legislación global, con muy pocas excepciones, que lo alimenta, y el monstruo, pavorosamente, siempre tiene hambre.

En Vietnam, los estadounidenses sufrieron once bajas diarias durante toda una década. El 11 de septiembre de 2001, el terrorismo yihadista asesinó a 3000 personas, y el 11 de marzo de 2004 acabó con la vida de otras 190 en Madrid. Son cifras dolorosas pero marginales si las comparamos con los 300 y 3500 soldados que perdían diariamente Estados Unidos y Alemania en la última guerra mundial. 
Pues bien, las cifras de víctimas por grooming son abrumadoramente más altas. Considérese que en promedio un pederasta digital daña a 40 niños y que las secuelas del chantaje, la humillación, el abuso se mantienen por décadas.

$¿$ Cabe mantener el mismo modelo de derecho penal para enfrentar a este tipo de delincuentes que abiertamente se comportan como enemigos?

Los Estados deben capacitar a los profesores y los padres en la necesaria educación de prevención. Los niños deben ser preparados, alertados respecto de la existencia de monstruos cuyo propósito es dañarlos.

Ante el primer intento de contacto, el menor debe saber cómo actuar, a dónde acudir, cómo buscar y obtener ayuda. Debe saber que nadie lo castigará ni lo juzgará por eso, que él no es culpable de una situación como esa y que, más bien, rompiendo el silencio se convierte en un héroe porque ayuda a evitar que esto se repita y afecte a otros menores. De nada sirve la incriminación de conductas, cuando el fin último es erradicar dichas prácticas, si no educamos a los potenciales sujetos pasivos para evitar directamente su victimización primaria.

Desde nuestro enfoque, el pederasta es un foco de peligro que debe ser neutralizado por todos los países con un estatuto jurídico distinto al actual, pero sin caer en el uso de propuestas huérfanas de toda base científica para limitar el problema, como la abanderada por el propio Sarkozy, que sugiere como solución la castración química, lo cual no resuelve nada, dado que el abusador sexual puede agredir a un menor o a otro adulto con cualquier elemento que haga las veces del órgano sexual, porque "las vías neuronales que modulan la conducta agresiva y la sexual son las mismas. Con la castración química no se inhiben los impulsos de la agresión, que se canalizan de otra manera, así que esa no es la solución"65.

En ese sentido, posiciones como las de Reynolds en el sentido de perseguir a los pederastas con líneas similares a las de la Patriot Act ${ }^{66}$ no pueden sino ser rechazadas desde la más simple lógica jurídica penal, pues despojar al detenido de su derecho a un juicio reglado, con acceso a las pruebas, con elección de un abogado de su confianza y un largo etcétera, convertiría cualquier sentencia en nula. Esto jamás ha sido parte de la propuesta jakobsiana, y es necesario reiterarlo.

65 Vázquez Mezquita, Blanca. Abuso sexual infantil: evaluación de la credibilidad del testimonio. Estudio de 100 casos, Valencia, Centro Reina Sofía para el Estudio de la Violencia, 2004.

66 Reynolds, A. M. "Child Predators after 9/11: Recognizing Child Predators as Domestic Terrorists and Empowering Law Enforcement with the Tools to Stop Them", en Children's Legal Rights Journal, 24, 2, 2004, pp. 37 y ss.; Villacampa Estiarte, Carolina. "Propuesta sexual telemática a menores u online child grooming: configuración presente del delito y perspectivas de modificación", Estudios Penales y Criminológicos, n. ${ }^{\circ}$ 34, 2014, disponible en [https://revistas.usc.gal/index.php/epc/article/view/2094]. 
Se necesita una regulación internacional unificada para poder combatir este fenómeno. Las operaciones judiciales y policiales necesariamente deben ser de cooperación, dado que estos delincuentes se asocian en verdaderos carteles globales para poder comercializar el dolor de sus víctimas a través de la pornografía infantil y otras formas de desviación.

David Canter y Kim Rossmo sostenían en un conocido paradigma de investigación criminal que los lugares del delito están vinculados con el domicilio del criminal o con algún lugar importante para él. Pero lamentablemente en este tipo de casos no podemos aplicar el "círculo de Canter", que consiste en marcar en un mapa los escenarios de delitos previos y tomar los dos puntos más alejados entre sí, luego se traza una línea recta que configurará el diámetro desde cuyo centro se determinará el espacio final dentro del que quedan las áreas de actuación y los puntos de anclaje del criminal. Sin duda esa técnica era muy efectiva en décadas previas, cuando los delincuentes sexuales tenían que salir de sus cuevas a buscar a sus víctimas y por ello se sentían mucho más cómodos cometiendo sus delitos en sectores un tanto cercanos a sus residencias, en los que conocían detalles relativos a controles policiales, tráfico vehicular, zonas oscuras para aumentar las posibilidades de no ser descubiertos; pero hoy estamos ante un fenómeno delictivo diverso, ante un enemigo mucho más poderoso. "Es el lugar, en este caso, 'el no lugar', el que define y marca los eventos sociales en él realizados y el que, por tanto, configura también como distinta la delincuencia en él ejecutada" 67 , nos dirá Miro Llinares con su milimétrica capacidad descriptiva. Frente a esto, ¿debe la sociedad mantenerse anclada a cadenas conceptuales que le impiden proteger efectivamente la paz social? Schilling sostiene que es inexcusable obligación del legislador dar respuestas adecuadas, que habiliten al Estado a lanzar un mensaje claro a los que pretenden impulsar y sonreír ante la hecatombe que generan "los efectos remotos de la acción destructiva y acumulativa del crimen contemporáneo", para lo cual expresa magistralmente: “Anticipemos la representación de este mal: terroristas y narcotraficantes más ricos que pueden adquirir todo tipo de armas, incluso de destrucción masiva; pederastas y violadores en serie con un mayor poder tecnológico de comunicación y rastreo de niños y víctimas sexuales; criminales reincidentes con un mayor conocimiento de las técnicas policiales y del Derecho para vulnerar su control" 68 .

El minotauro digital puede cometer sus delitos desde Madrid y dañar a cientos de niños en Cali, Lima o Budapest. Esto es clave para que usted entienda que sin cooperación policial internacional se hace mucho más difícil neutralizarlos. Estamos hablando de un dragón que en el pasado sentía vergüenza de lo que hacía, sufría serios conflictos emocionales por la culpa, por el convencimiento de actuar cobardemente; pero el

67 Miró Llinares, F. El cibercrimen: fenomenología y criminología, cit., pp. 28 y 29.

68 Schilling, Mario. El nuevo derecho penal del enemigo, Santiago, Librotecnia, 2010, p. 174. 
monstruo hoy puede encontrar fácilmente adhesión, comprensión y hasta aplausos en otros de su misma condición, a quienes encuentra con solo deslizar sus dedos por una pantalla, lo cual ha generado redes de pederastas tan o más intricadas que las de los carteles de la droga o los grupos terroristas. La mayoría de pederastas que se organizan en grupos transnacionales utilizan protocolos para no ser atrapados. Por razones que usted comprenderá no podemos desarrollar el tema aquí en profundidad, solo a efectos andragógicos diremos que hasta hace pocos años se valían de la Internet Protocol Security (IPsec), que facilita la impunidad porque refuerza la seguridad del real usuario a través de algoritmos de cifrado robustos y un sistema de autentificación complejo. Solo a modo de ejemplo, porque protocolos hay para todos los gustos, IPsec posee dos métodos de encriptado, modo transporte y modo túnel. Asimismo soporta encriptado de 56 bit y 168 bit (triple DES), lo cual además les da la posibilidad de aparecer conectados a un ordenador en Lituania cuando están cometiendo abuso sexual infantil con diversas variantes en Colombia o Laos. Es meridiano comprender que se necesita un cuerpo investigativo especializado, una Unidad de Víctimas Especiales que, al amparo de una legislación de avanzada, tenga un entrenamiento profesional que permita identificar y combatir estos focos, que vaya de la mano de las conocidas "sting operations", operativos policiales específicamente dirigidos a cazar predadores sexuales, consistentes en que uno o varios agentes policiales crean falsos perfiles de adolescentes en determinadas redes sociales para detectar a posibles pedófilos en busca de menores, llegando incluso dichos agentes encubiertos a provocar el contacto con el presunto pedófilo. Al menos la Ley de Enjuiciamiento Criminal de España, introducida por la Ley Orgánica 13/2015, establece en su artículo 282 que cuando se trate de actividades propias de delincuencia organizada, el juez de instrucción competente, así como la Fiscalía (dando cuenta inmediata al instructor), mediante resolución fundada y atendiendo a criterios de necesidad en la investigación que refiere, podrá amparar la actuación del denominado agente encubierto, que "estará exento de responsabilidad criminal por aquellas actuaciones que sean consecuencia necesaria del desarrollo de investigación" y además queda autorizado para "intercambiar o enviar por sí mismo archivos ilícitos por razón de su contenido y analizar los resultados de los algoritmos aplicados para la identificación de dichos archivos ilícitos". Como vemos, se va entendiendo, aunque sea en forma muy lenta, la necesidad de enfrentar a un enemigo cada vez más poderoso y perjudicial como entre otros, el que se esconde en la deep web. El agente 2.0 o agente virtual, desde la concepción del garantismo radical, estaría induciendo al pederasta a cometer delitos, pero no se toma en consideración que estos no van a ser capturados porque el agente lo decide, por su color de piel, en razón de su raza o culto religioso, sino por los contactos que mantendrá con claro tinte lúbrico, disfrazado de niño con alguien que como él también está disfrazado pero, a diferencia del primero, no para dañar, sino, por el contrario, para evitar que éste destruya la vida de más menores. 


\section{REFERENCIAS}

Ambos, Kai. "Derecho penal del enemigo", en M. Cancio Meliá y C. Gómez-Jara Díez (coords.), Derecho penal del enemigo: el discurso penal de la exclusión, vol. 1, Montevideo-Buenos Aires, B de F, 2006, p. 11916.

Antolisei, Francesco. "Pena e misure di sucurezza", en Revista italiana di diritto penale, 1933.

Betancor Curbelo, Diego. "Derecho y sociedad, factores recíprocos. La sociología del derecho en la formación del jurista", en Revista de Ciencias Jurídicas de la Universidad de las Palmas de Gran Canaria, n. . 2, 1997.

Boguñá Nieto, Marta. La custodia de seguridad, 3 cuestiones fundamentales, tesis de grado de derecho de la Universidad Pompeu Fabra, Barcelona, 2013, disponible en [https://repositori.upf.edu/bitstream/handle/10230/23435/TFGDRET_Bogu\%C3\%B1a _2012_2013.pdf?sequence=1\&isAllowed=y].

Carral, Juan José. "En la mente de un pederasta, estudio realizado con varios prisioneros por estos delitos", CIPREA, 2017, disponible en [http://www.madrid-psicoterapia. com/wordpress/la-mente-pederasta/].

Craissati, J.; Mcclurg, G. y Browne, K. "Characteristics of perpetrators of child sexual abuse who have been sexually victimized as children", Sexual Abuse, 2002, disponible en [https://journals.sagepub.com/doi/abs/10.1177/10790632020140030 3 ? journalCode $=\mathrm{saxb}$.

Cuenca Padilla,A. El nuevo delito de grooming del artículo 183 bis del Código Penal, trabajo fin de grado, Universidad Autónoma de Barcelona, 2014.

De la Gándara, Beatriz. "Algunas consideraciones acerca de los fundamentos teóricos del sistema de la teoría del delito de Jakobs", en ADPCP, vol. L, 1997.

Dolz Lago, M. J. "Un acercamiento al nuevo delito de child grooming. Entre los delitos de pederastia", Diario La Ley, n. ${ }^{\circ} 7575$.

Egan, V., Kavanagh, B. y Blair, M. "Sexual offenders against children: the influence of personality and obsessionality on cognitive distortions", Sexual Abuse, 2005, disponible en [https://pubmed.ncbi.nlm.nih.gov/16121837/].

Finkelhor, D. Child Sexual Abuse: New Theory and Research, New York, The Free Press, 1984, disponible en [https://scholars.unh.edu/soc_facpub/339/]. 
Fletcher, George P. Washington Post, edición impresa del 12 de octubre del 2001, con idéntico texto en Fletcher, Justice in the Face of Enemy Fire, manuscrito inédito, 2005.

Gimbernat Ordeig, E. Delitos cualificados por el resultado y causalidad, 2. ed., Colección Maestros del Derecho Penal, Buenos Aires, Editorial B de F.

González Tascón, M. M. "El nuevo delito de acceso a niños con fines sexuales a través de las TIC", en Estudios Penales y Criminológicos, vol. XXXI, Santiago de Compostela, 2011.

Hegel, Georg Wilhelm Friedrich. Vorlesungen Uber Rechtsphilosophie 1818-1831: Die Rechtsphilosophie Von 1820, Mit Hegels Vorlesungsnotizen 1821-1825, 1974.

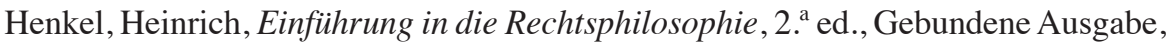
1977.

Izuzquiza, Ignacio. La sociedad sin hombres. Niklas Luhmann o la teoría como escándalo, Barcelona, 1990.

Jakobs, Günther, Statileche Strafe: Bedeutung und Zweck (Nordrhein-Westfälische Akademie der Wissenschaften und der Künste - Vorträge: Geisteswissenschaften, Paderborn, 2004.

Jakobs, Günther. La imputación objetiva en Derecho penal, traducción de Manuel Cancio Meliá y estudio preliminar de Carlos Suárez González y Manuel Cancio Meliá, Madrid, 1996.

Jakobs, Günther. “¿Cómo protege el derecho penal y qué es lo que protege?”, en El pensamiento filosófico y jurídico-penal de Günther Jakobs, Carlos Daza (ed.),

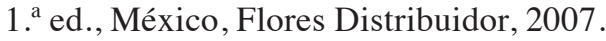

Jakobs, Günther. "La ciencia del derecho penal ante las exigencias del presente", en Dogmática de derecho penal y la configuración normativa de la sociedad, traducción de Teresa Manso, Madrid, Civitas, 2004.

Jescheck, Hans Heinrich. Lehrbuch des Strafrechts: allgemeiner Teil, citado en Cano Paños, M. A. El marco jurídico y criminológico de la custodia de seguridad en el derecho penal alemán.

Kant, I. Sobre la paz perpetua, Kimana Zulueta (trad.), Ediciones Akal.

Kierkegaard, S. "Cybering, Online Grooming and Ageplay”, en Computer Law and Security Report, 41, 2008, disponible en [https://www.sciencedirect.com/science/ article/abs/pii/S0267364907001136]. 
Klaus, Günther. "Straf(ab)gründe. Rechtsphilosphie in der Diskussion”, en Siller/ Seller (Hrsg.), Rechtsphilosophische Kontroversen der Gegenwart, Baden-Baden, 1999.

Kruger, Th. y Schiffer, B. "Neurocognitive and personality factors in homo- and heterosexual pedophiles and controls", en The Journal of Sexual Medicine, vol. 8, n. ${ }^{\circ}$ 6, 2011, 1650-1659, doi:10.1111/j.1743-6109.2009.01564.x1.

Luhmann, Niklas. Ökologische Kommunikation Kann die moderne Gesellschaft sich auf ökologische Gefährdungen einstellen?

Luhmann, Niklas. Complejidad y modernidad. De la unidad a la diferencia, Josetxo Beriain y José María García Blanco (trads.), Madrid, Trotta, 1998.

Luhmann, Niklas. Zweckbegriff und Systemrationalität: über die Funktion von Zwecken in sozialen Systemen, 1973.

Magro Servet, V. "El 'grooming' o ciber acoso infantil, el nuevo artículo 183 bis del Código Penal”, en Diario La Ley, n. ${ }^{\circ}$ 7492, Sección Tribuna, 20 de octubre de 2010.

Mellon, M. W.; Whiteside, S. P. y Friedrich, W. "The relevance of fecal soiling as an indicator of child sexual abuse: A preliminary analysis", Developmental and Behavioral Pediatrics, 2006, disponible en [www.researchgate.net/publication/7267259_ The_Relevance_of_Fecal_Soiling_as_an_Indicator_of_Child_Sexual_Abuse].

Mendoza Calderón, S. El derecho penal frente a las formas de acoso a menores. Bullying, ciberbullying, grooming y sexting, Valencia, Tirant lo Blanch, 2003.

Miró Llinares, F. El cibercrimen: fenomenología y criminología de la delincuencia en el ciberespacio, Madrid, Marcial Pons, 2012.

Mizrahi, Esteban. Los presupuestos filosóficos del derecho penal contemporáneo, Buenos Aires, Universidad Nacional de la Matanza, 2012.

Montealegre, Eduardo. Estudios sobre las obras de Günther Jakobs y Claus Roxin y sobre las estructuras modernas de imputación, Bogotá, Universidad Externado de Colombia, 2004.

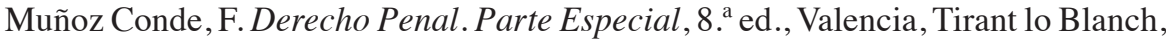
2010 .

Müssig, Bernd. "Derecho penal del enemigo: concepto y fatídico presagio. Algunas tesis”, en M. Cancio Meliá y C. Gómez-Jara Díez (coords.), Derecho penal del enemigo: el discurso penal de la exclusión, vol. 2, Montevideo-Buenos Aires, B de F, 2006. 
Núñez Fernández, José. "Presente y futuro del mal llamado delito de ciberacoso a menores: análisis del artículo 183 bis CP y de las versiones del Anteproyecto de Reforma de Código Penal de 2012 y 2013", artículo que se enmarca en el proyecto de investigación Garantías penales en la creación, aplicación y ejecución del Derecho penal de la Unión Europea, con referencia DER2012-32977, financiado por el Ministerio de Economía y Competitividad.

O'Connell, R. A Typology of Cyberexploitation and Online Grooming Practices, Preston, Universidad de Lancashire, también en repositorio de tesis de la National Children's Advocacy Center, disponible en [www.jisc.ac.uk/uploaded_documents/ lis_paperjprice.pdf].

Pawlik, Michael. Ciudadanía y Derecho Penal, Barcelona, Atelier Libros Jurídicos, 2016.

Pawlik, Michael. Das Unrecht des Burges, 2012.

Pérez Arroyo, Miguel. Las medidas de seguridad en el derecho penal peruano, Instituto de Derecho Penal Europeo e Internacional, Colección Direito e Ciudadania, III, n. ${ }^{\circ}$ 7, 1999-2000.

Polaino-Orts, Miguel. Derecho Penal como sistema de autodeterminación personal, Lima, Ara Editores, 2012.

Reynolds, A. M. “Child Predators after 9/11: Recognizing Child Predators as Domestic Terrorists and Empowering Law Enforcement with the Tools to Stop Them", en Children's Legal Rights Journal, 24, 2, 2004.

Rosenberg, A. D.; Abell S. C. y Mackie J. K. "An examination of the relationship between child sexual offending and psychopathy", en Journal of Child Sexual Abuse, disponible en [https://www.tandfonline.com/doi/abs/10.1300/J070v14n03_03,2005].

Salter, A. Transforming Trauma: A Guide to Understanding and Treating Adult Survivors of Child Sexual Abuse, Newbury Park, California, Sage, 1995.

Schilling, Mario. El nuevo derecho penal del enemigo, Santiago, Librotecnia, 2010.

Schünemann, Bernd. Derecho penal contemporáneo. Sistema y desarrollo. Peligro y límites, Buenos Aires, Hammurabi, 2010.

Silva Sánchez, Jesús M. Aproximación al Derecho penal contemporáneo, Barcelona, JM Bosch, 1992. 
Silva Sánchez, Jesús M. "Del Derecho abstracto al Derecho 'real'”, Indret, n. o 377 , Barcelona, Universidad Pompeu Fabra, 2006.

Stoos, Carl. Lehrbuch des Osterreischischen Strafrecht, Viena-Leipzig, 1910.

Tamarit Sumalla, J. M. "Los delitos sexuales. Abusos sexuales. Delitos contra menores (arts. 178, 180, 181, 183, 183 bis)", en Quintero Olivares, G. La reforma penal de 2010: análisis y comentarios, Aranzadi-Thomson Reuters, Cizur Menor, 2010.

Vázquez Mezquita, Blanca. Abuso sexual infantil: evaluación de la credibilidad del testimonio. Estudio de 100 casos, Valencia, Centro Reina Sofía para el Estudio de la Violencia, 2004.

Villacampa Estiarte, Carolina. "Propuesta sexual telemática a menores u online child grooming: configuración presente del delito y perspectivas de modificación", en Estudios Penales y Criminológicos, 34, 2014, disponible en [https://revistas.usc. gal/index.php/epc/article/view/2094].

Ward, T. et al. "A descriptive model of the offense chain for child molesters", en Journal of Interpersonal Violence, 10(4), disponible en [https://doi.org/10.1177/08 8626095010004005].

\section{Otros}

Centro Cibernético Policial de Colombia. Datos estadísticos de modalidades de cibercrimen no tipificadas en la Ley 1273 de 2009. Estudio de datos de los años 2014-2015.

Dictamen de la Comisión del Congreso de los Diputados de España del 28 de abril de 2010 .

Federación Nacional de Abogados del Ecuador. "Estudio del abuso sexual infantil a través de internet", en Revista Advocatus, n. ${ }^{\circ}$ 4, 2017.

Ministerio de Telecomunicaciones del Ecuador, [http://www.telecomunicaciones. gob.ec/en-el-ecuador-60-de-cada-100-usuarios-usan-internet-una-vez-al-dia/] (consulta: 03/07/2013).

Oxford Advanced Learner's Dictionary, Oxford University Press, 1997. 